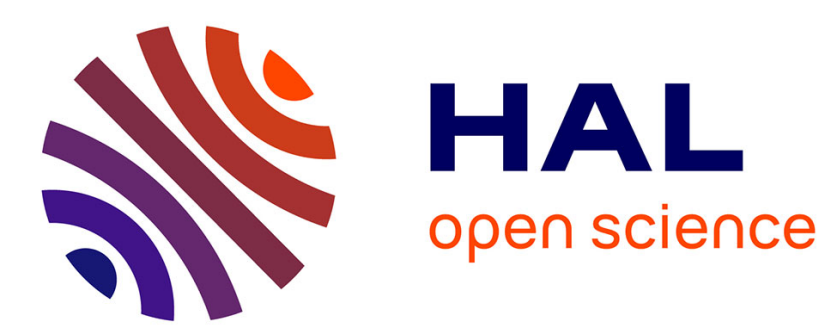

\title{
Dynamic Estimation of the Yield in Precision Viticulture from Mobile Millimeter-Wave Radar Systems
}

Dominique Henry, Hervé Aubert, Patrice Galaup, Thierry Véronèse

\section{To cite this version:}

Dominique Henry, Hervé Aubert, Patrice Galaup, Thierry Véronèse. Dynamic Estimation of the Yield in Precision Viticulture from Mobile Millimeter-Wave Radar Systems. IEEE Transactions on Geoscience and Remote Sensing, 2022, 60, pp.4704915. 10.1109/TGRS.2021.3133017 . hal-03518745

\author{
HAL Id: hal-03518745 \\ https://hal.laas.fr/hal-03518745
}

Submitted on 10 Jan 2022

HAL is a multi-disciplinary open access archive for the deposit and dissemination of scientific research documents, whether they are published or not. The documents may come from teaching and research institutions in France or abroad, or from public or private research centers.
L'archive ouverte pluridisciplinaire $\mathbf{H A L}$, est destinée au dépôt et à la diffusion de documents scientifiques de niveau recherche, publiés ou non, émanant des établissements d'enseignement et de recherche français ou étrangers, des laboratoires publics ou privés. 


\title{
Dynamic Estimation of the Yield in Precision Viticulture from Mobile Millimeter-Wave Radar Systems
}

\author{
Dominique Henry, Hervé Aubert, Patrice Galaup and Thierry Véronèse
}

\begin{abstract}
This paper reports the yield estimation of vineyards from using a mobile millimeter-wave radar system. The proximal radar sensor is a $122 \mathrm{GHz}$ FM-CW radar mounted on a rover that moves along the furrows between vine plants. The proposed yield estimation is based on the classification of radar echoes measured for various grape varieties, for different meteorological conditions, and at different stages of grape development. As yield estimation errors are found to be lower than $10 \%$, the proposed radar technique is suitable for precision viticulture applications.
\end{abstract}

Index Terms - classification, passive microwave remote sensing, precision agriculture, precision viticulture, radar imaging, remote sensing, radar polarimetry.

\section{INTRODUCTION}

$\mathbf{P}$ RECISION agriculture (PA) is a well-known concept originally based on the observations of spatial variabilities within agricultural plots [1]. PA was developed with the help of localization techniques, such as precision Global Positioning System (GPS) [2], remote sensing technologies and variablerate technologies [3]. Precision viticulture (sometimes referred as PV) is part of PA, but specifically dedicated to viticulture and vineyard issues. It was applied for the first time by Bramley et al. [4] to map variabilities of the yield collected and measured by a grape yield monitor. Many data of interest in vineyards can be remotely measured with ground-based systems, such as vine vigor [5], water stress [6], apparent soil electrical conductivity [7] or anthocyanin concentration [8].

A fundamental feature of vineyard is its yield. The term yield in viticulture usually refers to the mass or volume of harvested grapes per cultivated area. Throughout this paper, it is the mass (in kilograms) of harvested grapes. Yield is monitored to predict the annual profitability, to estimate losses during severe meteorological conditions, to anticipate the logistic for the harvest, and in some circumstances (e.g. for obtaining the appellation of origin label) to regulate the yield per vine plant. Before the harvesting, the yield is usually estimated from the detection of grapes using optical systems. One of such optical detection system was originally proposed in 2006 [9], and nowadays smartphone applications are developed for counting 3D reconstructed grape berries [10]. Optical sensors offer actually many advantages: they are cheap, easy to use, and the physical interpretations of measurement can

D.Henry, H.Aubert are with LAAS-CNRS and Toulouse University, Toulouse, France. P.Galaup and T.Véronèse are with Ovalie Innovation, Auch, France.

Manuscript received June 03, 2021; be easily performed. However, it may have some drawbacks for the yield estimation. First, images of grapes are generally two-dimensional and do not render a volume. Nevertheless, it can be replaced by stereovision cameras [11]. Moreover, grapes hidden by leaves or woods are hardly detectable and tying might be necessary to remove leaves before the optical measurement. Because of the variable luminosity in the vineyard, camera calibrations may also be required for properly detecting grapes. Last but not least, grape detection may also be difficult for white and green varieties since they share the same colors with the surrounding vegetation.

To estimate the yield, another solution investigated by the Authors of the present study was to use various proximal ground-based radar sensors [12] operating at submillimeter-waves $(24 \mathrm{GHz})$ and millimeter-waves $(77 \mathrm{GHz}$ and $122 \mathrm{GHz}$ ). At these frequencies, these sensors are able to detect centimeter-size electromagnetically reflective objects, such as vine grapes. Other approaches to measure the yield with radar are also investigated at lower frequencies [13]. Moreover, a volume information can be derived from radar data from the beamscanning of the scene. At millimeter-wave frequency ranges, grapes hidden by leaves can be detected. Finally, unlike optical sensors, radars are not sensitive to ambient luminosity or color, and no calibration is needed.

Our previous works [12] show that $122 \mathrm{GHz}$ proximal frequency-modulated continuous-wave (FM-CW) groundbased radar sensors with large modulation bandwidth may lead to the accurate estimation of the yield with a precision lower than $10 \%$. However, on the one hand, the sensors were stationary and on the other hand, the beamscanning was performed vine plant per vine plant. Consequently, the required measurement time was not suitable in practice for estimating the yield of large vineyards. Moreover, yield statistical estimators were built with few radar data obtained from a very limited number of vine plants ( 25 or less) and have not been validated for larger data set and various meteorological conditions. For these reasons, we investigate in this paper the estimation of the yield in viticulture by using a millimeterwave $(122 \mathrm{GHz})$ radar sensor mounted on a remotely controlled rover that moves along the furrows between vine rows. With such system, patented by Véronèse et al. [14], large amount of data can be collected and new yield statistical estimators can be both defined and validated. With the proposed dynamic estimation, several novelties are pointed out regarding to [12]. First new specific issues need to be solved to accurately derive the yield from radar measurement, such as the compensation of 
eventual variation of the rover's speed during the displacement along the furrows, or the investigation of the validity domain of new yield statistical estimators. The beamscanning is also modeled in order to take into account many key parameters in the estimation of the yield. It also implies the development of new signal processing techniques to estimate the yield. In particular, the proposed classification of segmented radar echoes is novel and might be applied to various applications. Finally, the present study is based on significantly larger number of measurement data obtained during a two-year period. Indeed, a large amount of radar data was collected in 2019 and 2020 from various grapes varieties of the same vineyard and at different stages of grape development. This allowed us to define, test and validate a more accurate yield estimator. The radar measurements, which were carried out from July to September for various stages of grape growth, have been used to investigate the limitations of the proposed yield estimator.

The paper is organized in three Sections. Section II describes the material and methods. It includes the description of the vineyard and the dozen of black and white grape varieties that have been selected for various meteorological conditions. The beamscanning of the radar is then described and simulated in order to design the system and determine its key parameters, such as, the speed of the rover and the measurement repetition time of the radar. Section III focuses on signal processing steps leading to the yield statistical estimation. It includes the segmentation of radar echoes with isolines (as defined in [15]) and the classification of radar echoes into two classes referred as clutter and grapes and clutter. Finally, following the methodology proposed by the Authors in [16], the precision of the yield estimation is analyzed from various configurations of transmitted and received electric fields. In Section IV, the precision of yield estimation is discussed.

\section{Material And Methods}

\section{A. Vineyard Description}

Measurements are performed in a plot of the IFV (Vine and Wine French Institute, France) near the city of Gaillac (SouthWest of France) during 2019 and 2020 summers. This plot is a collection of multiple varieties of black and white grapes sorted by vine row. Each vine row is composed of 48 to 54 vine plants separated by a distance of 1 meter. The furrows (that is, gaps between rows) are 2 meters large. Moreover, the soil between rows is alternatively ploughed and grassy. The ground-truth value of the yield is manually determined during the harvest (in 2019 and 2020) and for six consecutive vine plants. Throughout the paper, these six consecutive vine plants are referred as a group of vine plants. The tying (known as double cordon de Royat) is the same for all vine plants: vertical metallic stakes are located between each group and three horizontal metallic wires support the vine plants. A photograph of a vine row is given in Fig 1. As observed on this picture, leaves are numerous and hide the grapes. The total yield of each vine row is reported in Table I. Each vine row is composed of 8 to 9 groups of 6 vineplants, and the mean and standard deviation per group are also reported. Large yield differences are observed, depending on the grape variety and year. As an example, vine row $R 12$ (Tempranillo variety) has yields of $81.9 \mathrm{~kg}$ in 2019 and $193.5 \mathrm{~kg}$ in 2020 .

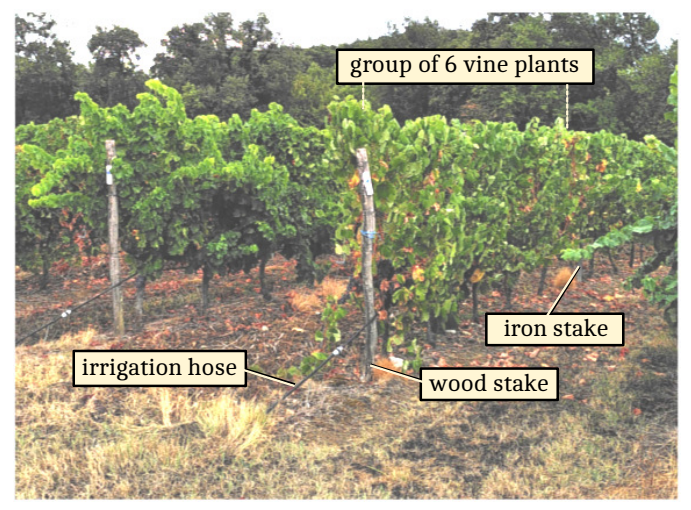

Fig. 1. Typical vine row (Négrette variety, 08-31-2020) at the IFV (Vine and Wine French Institute, France) vineyard where dynamic radar measurements have to be performed for estimating the yield before the harvest.

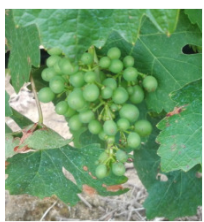

(a)

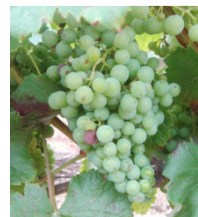

(b)

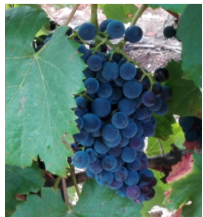

(c)

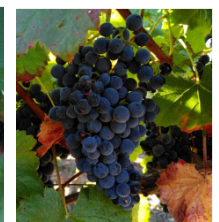

(d)
Fig. 2. Photographs of the same vine grape at four different periods of the year: (a) 07-01-2020, (b) 07-22-2020, (c) 08-17-2020 and (d) 09-07-2020

Moreover, the yield is estimated at different periods of the year, and sometimes for different measurement configurations, as indicated in Table II. During the radar measurement, relevant meteorological conditions (such as wet weather or high humidity) as well as the polarization configurations ( $V V$ and $H H)$ and minimal $\left(\theta_{\min }\right)$ and maximal $\left(\theta_{\max }\right)$ elevation angles are stored (see Section II-B for the definition of the polarization configurations, and Section II-D for the definition of elevation angles). In 2019, the radar measurements were performed at the end of the summer and consequently, the grapes have reached their final volume. In 2020, they started earlier (early July) and therefore, the yield estimation is expected to be less accurate than one derived from the radar data obtained in 2019. This can be illustrated in Fig 2 which shows photographs of the same grape taken from early July to late August. Note that the grapes reach their final volume around mid-August.

\section{B. Reader Description}

The reader used for the yield estimation is the $122 \mathrm{GHz}$ FM-CW radar (EasyRadar) manufactured by Silicon Radar $\mathrm{GmbH}$ [17]. It transmits a chirp at the base frequency $f_{b}$ of $119.3 \mathrm{GHz}$ and the modulation bandwidth $B$ of $6.5 \mathrm{GHz}$. The theoretical depth resolution is $d=2.3 \mathrm{~cm}$. The frequency modulation is a saw-tooth signal with the up-ramp duration $T_{u p}=50 \mu \mathrm{s}$. The received signal is averaged from a group of 
TABLE I

YIELDS (IN KILOGRAMS) OF VINE ROWS MANUALLY MEASURED IN 2019 AND 2020 AFTER THE HARVEST

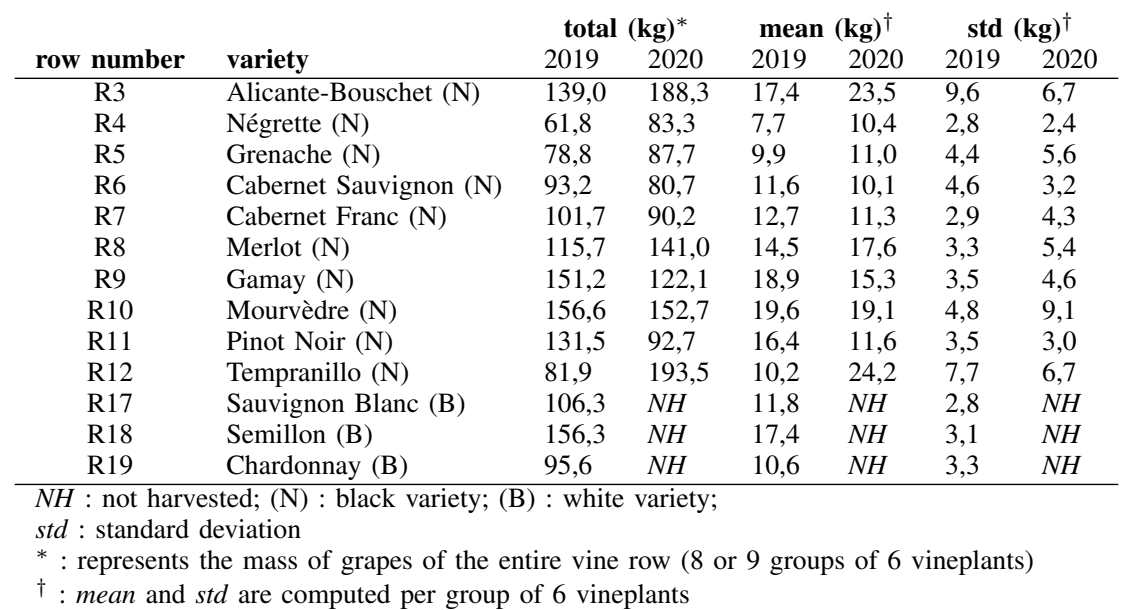

TABLE II

RADAR MEASUREMENTS CONFIGURATIONS USED IN 2019 AND 2020

\begin{tabular}{lllll} 
date $^{a}$ & $\theta_{\min }-\theta_{\max }$ & $\begin{array}{l}\text { polarization } \\
\text { configura- } \\
\text { tion }\end{array}$ & vine rows & notes \\
\hline $07-30-2019$ & $0^{\circ}-30^{\circ}$ & $\mathrm{HH}$ & $3-8$ & rain \\
$08-08-2019$ & $0^{\circ}-30^{\circ}$ & $\mathrm{HH}$ & $3-8$ & humidity \\
$08-22-2019$ & $10^{\circ}-40^{\circ}$ & $\mathrm{HH}$ & $3-4$ & \\
$08-27-2019$ & $10^{\circ}-40^{\circ}$ & $\mathrm{HH}$ & $3-1217-19$ & rain \\
$09-03-2019$ & $10^{\circ}-40^{\circ}$ & $\mathrm{HH}$ & $3-1217-19$ & \\
$09-12-2019$ & $10^{\circ}-40^{\circ}$ & $\mathrm{HH}$ & $3-1217-19$ & humidity \\
$09-23-2019$ & $10^{\circ}-40^{\circ}$ & $\mathrm{HH}$ & $3-1217-19$ & harvest* \\
$07-01-2020$ & $10^{\circ}-40^{\circ}$ & $\mathrm{VV}$ and HH & $3-12$ & \\
$07-08-2020$ & $10^{\circ}-40^{\circ}$ & $\mathrm{VV}$ and HH & $3-12$ & \\
$07-13-2020$ & $10^{\circ}-40^{\circ}$ & $\mathrm{VV}$ and HH & $3-12$ & \\
$07-22-2020$ & $10^{\circ}-40^{\circ}$ & $\mathrm{VV}$ and HH & $3-12$ & rain \\
$08-17-2020$ & $10^{\circ}-40^{\circ}$ & $\mathrm{VV}$ and HH & $3-12$ & \\
$08-31-2020$ & $10^{\circ}-40^{\circ}$ & $\mathrm{VV}$ and HH & $3-12$ & \\
$09-07-2020$ & $10^{\circ}-40^{\circ}$ & $\mathrm{VV}$ and HH & $3-12$ & losses \\
$09-30-2020$ & $10^{\circ}-40^{\circ}$ & $\mathrm{VV}$ and HH & $3-12$ & harvest \\
\hline \multicolumn{4}{l}{ : mm-dd-yyyy format } \\
*: 'harvest' means that grapes are harvested, thus they are not present \\
in the beamscanned scene
\end{tabular}

$N_{\text {ramp }}=4$ successive ramps transmitted with the repetition time $T_{\text {rep }}$ varying from $25 \mathrm{~ms}$ to $30 \mathrm{~ms}$. The number of signal samples is $N_{S}=256$ and the sampling of the beat frequency spectrum is $\frac{N_{S}}{2}=128$. The front-end of the radar is composed of $1 T x$ and $1 R x$ linearly-polarized and identical patch antennas combined with a dielectric lens of half-power beamwidth $\pm \theta_{A}=4^{\circ}$. The transmitted power is $P_{\text {out }}=5 \mathrm{dBm}$ and the gain of the receiver amplifier is set to $G_{R x}=56 \mathrm{~dB}$. During the measurements performed in 2019 , a single radar with horizontally polarized (transmitting and receiving) antennas was used. The corresponding polarization configuration is denoted here by $H H$. For the measurements performed in 2020 , two $122 \mathrm{GHz}$ FM-CW radars are used, one includes horizontally-polarized ( $T x$ and $R x$ ) antennas while the other uses vertically-polarized ( $T x$ and $R x$ ) antennas. Main parameters of the radar are reported in Table III. The polarization configuration available from the radar using V-polarized antennas is denoted by $V V$. As illustrated in Fig 3, the two radars $(H H 122 \mathrm{GHz}$ FM-CW radar and $V V 122 \mathrm{GHz}$ FM-CW radar) are mounted on a tilt mechanical platform and embedded to a rover which moves along the furrows of the plot.

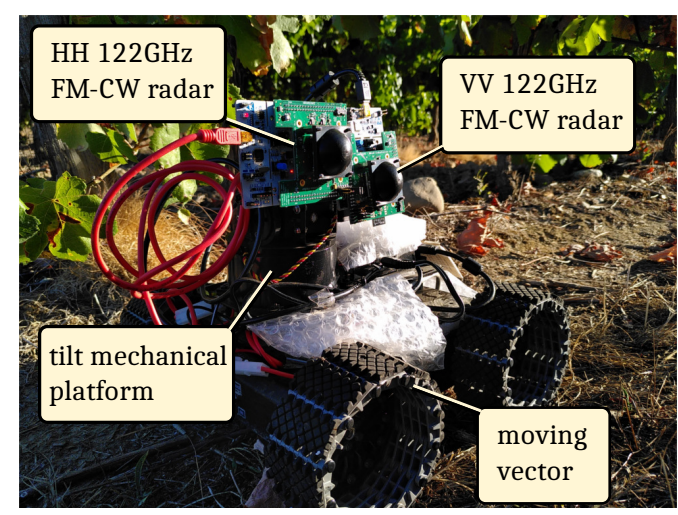

Fig. 3. Photograph of the mobile remote sensing system. In 2019, only the $H H$ FM-CW radar was used. In 2020, both $H H$ and $V V$ FM-CW radar were used during the experiment for the estimation of the yield.

TABLE III

RADAR MAIN PARAMETERS

\begin{tabular}{lll}
\hline base frequency & $f_{b}$ & $119.3 \mathrm{GHz}$ \\
modulation bandwidth & $B$ & $6.5 \mathrm{GHz}$ \\
depth resolution & $d$ & $2.3 \mathrm{~cm}$ \\
up-ramp duration & $T_{u p}$ & $50 \mu \mathrm{s}$ \\
successive averaged ramps & $N_{\text {ramp }}$ & 4 \\
repetition time & $T_{\text {rep }}$ & $25-30 \mathrm{~ms}$ \\
number of signal samples & $N_{S}$ & 256 \\
maximal range & $R_{\text {max }}$ & $2.9 \mathrm{~m}$ \\
transmitter power & $P_{\text {out }}$ & $5 \mathrm{dBm}$ \\
receiver gain & $G_{R x}$ & $56 \mathrm{~dB}$ \\
echo level range & $1_{\text {min }}-1_{\text {max }}$ & $-140 \mathrm{~dB}$ to $+80 \mathrm{~dB}$ \\
echo level resolution & $\delta_{l}$ & $1 \mathrm{~dB}$ \\
ADC frequency & $f_{A D C}$ & $5.143 \mathrm{MSamples.s}-1$ \\
half-power beamwidth (lens) & $\theta_{A} \varphi_{A}$ & $\pm 4^{\circ}$ \\
\hline
\end{tabular}

\section{Beamscanning Description}

To illustrate the beamscanning method, the geometrical approach illustrated in Fig 4 is proposed. One radar is located at the point $P_{k}$ and at height $h_{0}$ from the ground. We consider 
the point $M$ illuminated by the $k_{t h}$ chirp transmitted by the radar. The Cartesian coordinates of the point $M$ are then given by:

$$
\begin{aligned}
& x_{k}=v \times k \times T_{r e p} \\
& y_{k}=z_{0} \times \tan \left(\theta_{k}\right)+h_{0} \\
& z_{k}=z_{0}
\end{aligned}
$$

where $z_{0}$ denotes the normal separation distance between the radar and the vine row, $v$ is the time-dependent speed of the rover during its displacement along the $\mathrm{X}$-axis, and $\theta_{k}$ designates the elevation angle of the radar $T x$-antenna main lobe for the $k_{t h}$ chirp. This angle depends on the angular speed of the mechanical scanning, denoted by $\omega$, as follows:

$$
\theta_{k}=\left\{\begin{array}{l}
\theta_{\min }+\omega \times k \times T_{r e p}, \text { if } \Delta_{\theta} \leq \omega \times k \times T_{r e p} \\
\theta_{\max }-\omega \times k \times T_{r e p}, \text { if } \Delta_{\theta}>\omega \times k \times T_{r e p}
\end{array}\right.
$$

where $\theta_{\min }$ and $\theta_{\max }$ are respectively the minimal and maximal elevation angles (the angle $\theta_{k}$ is a periodic function of period $\frac{\Delta_{\theta}}{\omega}$ and magnitude $\left.\Delta_{\theta}=\theta_{\max }-\theta_{\text {min }}\right)$. Moreover, the surface centered at the point $M$ is considered in the XY-plane which is illuminated by the main lobe of the radar $T x$-antenna. The contour of this surface is approximately the ellipse of semi-axes $a_{k}$ and $b_{k}$ given by:

$$
\begin{aligned}
& a_{k}=\frac{1}{2}\left(\tan \left(\theta_{k}+\theta_{A}\right)-\tan \left(\theta_{k}-\theta_{A}\right)\right) \\
& b_{k}=z_{k} \times \tan \left(\varphi_{A}\right)
\end{aligned}
$$

where $\theta_{A}$ and $\varphi_{A}$ are the half-power beamwidths of the transmitting antenna in the vertical and horizontal planes, respectively.

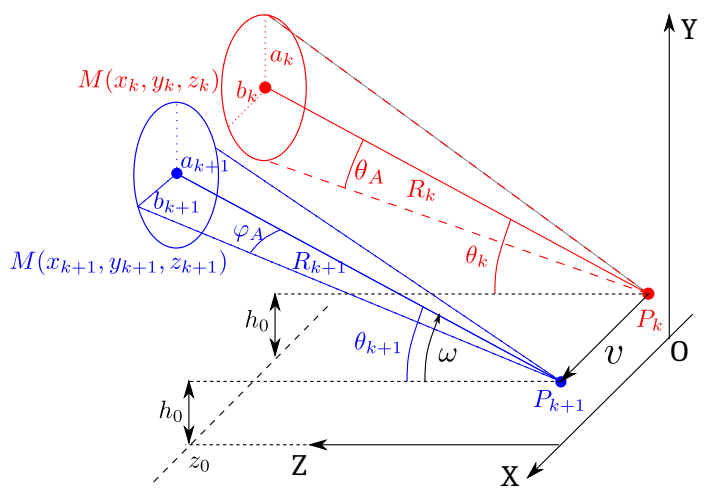

Fig. 4. Geometrical illustration of the beamscanning performed by the radar placed on the rover during its displacement along the furrows of the plot ( $v$ denotes the uniform speed of the rover along the $\mathrm{X}$-axis and the angular frequency of the $T x$ antenna rotation).

The ellipse is computed from the following parameters: $\theta_{A}=4^{\circ}, \varphi_{A}=4^{\circ}, T_{r e p}=30 \mathrm{~ms}, z_{0}=1.2 \mathrm{~m}, h_{0}=30 \mathrm{~cm}, \omega=60^{\circ} . \mathrm{s}^{-1}$, $\theta_{\min }=10^{\circ}$ and $\theta_{\max }=40^{\circ}$. It is displayed in Fig 5 when the rover moves from $X=0 \mathrm{~m}$ to $X=2 \mathrm{~m}$ at the constant speed $v$ of $0.2 \mathrm{~m} . \mathrm{s}^{-1}$ (Fig 5a) and $0.4 \mathrm{~m} . \mathrm{s}^{-1}$ (Fig 5b). These patterns are very similar to those obtained from the so-called SAR-mode scan imagery [18]. When the speed $v$ of the rover increases, a smaller surface of the scene at $z=z_{0}$ is illuminated. To estimate the grapes that are scanned by the radar during its displacement, we suppose that position $(x, y, z)$ of a grape is given by the multivariate probability density function (PDF) defined as follows:

$$
\mathcal{P}(x, y, z)=\mathcal{U}(x) \times \Phi_{\mu_{y}, \sigma_{y}}(y) \times \Phi_{\mu_{z}, \sigma_{z}}(z)
$$

where $\mathcal{U}$ is the uniform probability density function and $\Phi_{\mu, \sigma}$ the normal probability density function of mean $\mu$ and standard deviation $\sigma$. We assume here that the positions $x, y$ and $z$ are uncorrelated variables with parameters $\mu_{y}=0.8 \mathrm{~m}, \sigma_{y}=0.1 \mathrm{~m}$, $\mu_{z}=1.3 \mathrm{~m}$ and $\sigma_{z}=0.1 \mathrm{~m}$. According to equation (4), the average rate of scanned grapes is then given by:

$$
\Gamma_{\text {scan }}=\sum_{n=1}^{N_{\text {scan }}} \mathcal{P}\left(n_{x}, n_{y}, n_{z}\right)
$$

where $N_{\text {scan }}$ denotes the number of voxels in the scanned volume, and $\left(n_{x}, n_{y}, n_{z}\right)$ are the coordinates of the $n^{t h}$ voxel. $\Gamma_{\text {scan }}$ is displayed in Fig $6 \mathrm{a}$ as a function of the speed $v$ of the rover and repetition time $T_{\text {rep }}$. The rover moves along the $\mathrm{X}$-axis from $X=0 \mathrm{~m}$ to $X=6 \mathrm{~m}$ with a depth from $Z=1.0 \mathrm{~m}$ to $Z=1.6 \mathrm{~m}$. As expected, the average rate of scanned grapes increases when the rover decelerates, and the repetition time decreases. Markers in red and blue indicate mean value (crosses) and standard deviation (triangles) of $v$ and $T_{\text {rep }}$ for measurements obtained respectively in 2019 and 2020. For the measurements performed in 2019 , the average number of scanned grapes is estimated to $80 \%$ for the mean speed of $0.34 \mathrm{~m} . \mathrm{s}^{-1}$ and the mean repetition time of $26 \mathrm{~ms} \pm 0.9 \mathrm{~ms}$. In 2020, the average number of scanned grapes is estimated to $95 \%$ for the mean speed of $0.19 \mathrm{~m} . \mathrm{s}^{-1}$ and the mean repetition time of $32 \mathrm{~ms} \pm 0.9 \mathrm{~ms}$. These estimations remain valid as long as the probability density function $\mathcal{P}(x, y, z)$ is correctly modeled. If the proposed 3D PDF model is off-center with respect to the beam-scanned volume, the factor $\Gamma_{\text {scan }}$ decreases and the amount of unscanned grapes increases. As a result, estimation error increases. Moreover, our geometrical model used for designing the system and determining its key parameters (such as the repetition time of the radar) does not take into account the contributions of the electromagnetic clutter (wood, leaves, metallic wires, etc), the multiple reflections generated in the scene, the sidelobes of radar antennas, and the grapes that are hidden when the vine plant is scanned by the radar main lobe.

\section{Beamscanning Implementation}

The radar beamscanning of the vine rows described in Section II-C is performed mechanically, as illustrated in Fig $7 \mathrm{a}$. The rover is remotely controlled and drives along the furrows at the distance $R$ from vine plants and at the speed $v$. The CPU of the rover is a Raspberry Pi 3 Model B and the beamscanning routine runs with a Python3 environment. One or two $122 \mathrm{GHz}$ FM-CW radars are mounted on the tilt mechanical platform installed on the rover. The beamscanning in elevation is performed at the angular speed of $\omega=60^{\circ} . \mathrm{s}^{-1}$ and at height $h_{0}=30 \mathrm{~cm}$. The elevation angle goes alternatively up and down from the minimal elevation angle $\theta_{\min }=10^{\circ}$ to the maximal angle $\theta_{\max }=40^{\circ}$. Because tour rover was not able to drive on a ploughed soil, the beamscanning was performed 


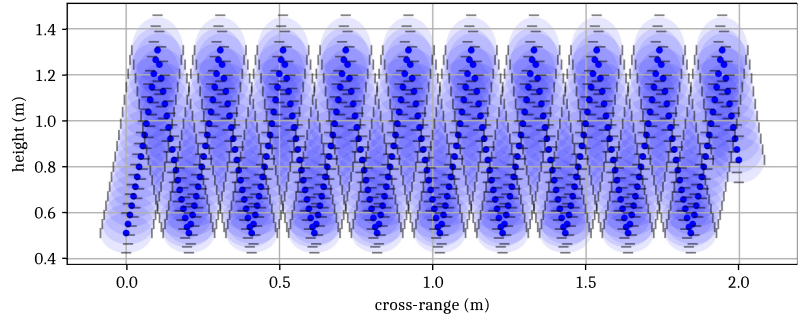

(a)

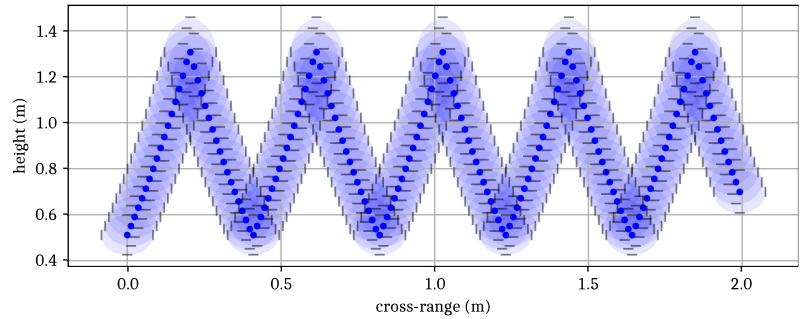

(b)

Fig. 5. Geometrical illustration of the illuminated surface in the $(X Y)$ plane at $z_{0}=1.2 \mathrm{~m}$ for (a) $v=0.2 \mathrm{~m} . \mathrm{s}^{-1}$ and (b) $v=0.4 \mathrm{~m} . \mathrm{s}^{-1}$. Regions in blue estimate the elliptical surfaces illuminated by the main lobe of the radar transmitting antenna, while blue circles indicate the point $M$. In black are displayed lines that are tangential to the semi-axes of the ellipses.

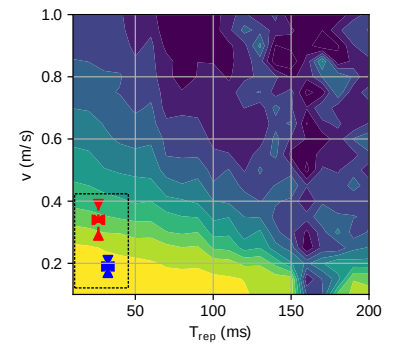

(a)

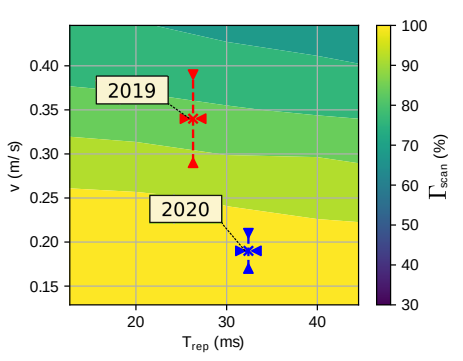

(b)
Fig. 6. (a) Average rate of scanned grapes $\Gamma_{\text {scan }}$ as a function of the rover speed $v$ and repetition time $T_{r e p}$ for $X=[0 \mathrm{~m}-6 \mathrm{~m}]$ and $Z=[1 \mathrm{~m}-1.6 \mathrm{~m}] .\left(\theta_{A}=4^{\circ}\right.$; $\varphi_{A}=4^{\circ} ; h_{0}=30 \mathrm{~cm} ; \omega=60^{\circ} . \mathrm{s}^{-1} ; \theta_{\min }=10^{\circ} ; \theta_{\max }=40^{\circ} ; \mu_{y}=0.8 \mathrm{~m} ; \sigma_{y}=0.1 \mathrm{~m}$; $\mu_{z}=1.3 \mathrm{~m} ; \sigma_{z}=0.1 \mathrm{~m}$ ); (b) Zoom of the left figure. Mean value (crosses) and standard deviation (triangles) for radar measurements performed in 2019 (in red) and 2020 (in blue) as a function of the rover speed and repetition time.

alternatively on the left or right sides of the vine row in order to drive the rover on grassy soil exclusively, as illustrated in Fig $7 \mathrm{~b}$. The distances travelled by the rover $d_{\text {back }}$ and $d_{\text {front }}$ are estimated by two wheel encoders integrated respectively on the left front and right back wheels. The speed of the rover is derived from the following equation:

$$
v=\frac{1}{2} \frac{d_{\text {back }}+d_{\text {front }}}{N_{\text {chirps }} \times T_{\text {rep }}}
$$

where $N_{\text {chirps }}$ is the total number of chirps transmitted by the radar during the measurement. In Fig 6a, the mean speed of the rover was found to be of $0.34 \pm 0.05 \mathrm{~m} . \mathrm{s}^{-1}$ in 2019 and $0.19 \pm 0.02 \mathrm{~m} . \mathrm{s}^{-1}$ in 2020 . Due to ground irregularities of the grassy soil traveled by the rover, the speed $v$ and height $h_{0}$ may vary during the measurement time. Note that $d_{b a c k}$ and $d_{\text {front }}$, and therefore $v$, are estimated with a time resolution representing an elevation cycle ( 0.5 second), as described in steps $(i i i)-(i v)$ of the flowchart in Fig 8.

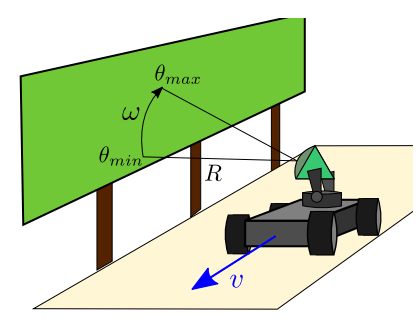

(a)

vine row $\square$ grassy soil $\square$ ploughed soil

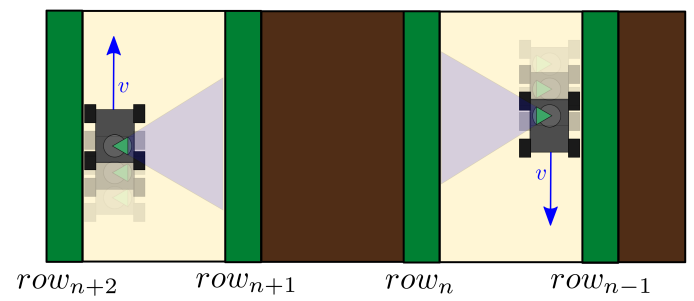

(b)

Fig. 7. (a) Illustration of the beamscanning of a vine row performed by the mobile remote sensing device (rover) at the speed $v$ and angular speed $\omega$. (b) Illustration of the beamscanning (top view). The beamscanning cannot be performed on a ploughed soil by the rover. Consequently, the beamscanning is performed alternatively on the left or right side of the vine row in order to drive the rover exclusively on grassy soil.

\section{YIELD EstimATION}

\section{A. Pre-processing of the Radar Image to Focus on the Range} of Interest

The radar image is derived from the so-called time-distance matrix $M_{T D}$ (dimensions $N_{\text {chirps }} \times N_{F F T}$ ) resulting from the measurement of $N_{\text {chirps }}$ beat frequency spectra (steps $(i)-(i i)$ in Fig 8). An example of radar image is displayed on Fig 9a from the measurement campaign performed in 09-07-2020 (R10 - Mourvèdre variety - group 5). To obtain this image, vine plants were beamscanned during $5.9 \mathrm{~s}$. The maximal range of interrogation is $R_{\max }=d \cdot \frac{N_{S}}{2}=2.95 \mathrm{~m}$. Echo levels of the vine plants are located at ranges between $1.2 \mathrm{~m}$ and $2.1 \mathrm{~m}$. We observe a range oscillation of the radar echoes due to the movement of the tilt mechanical platform, which modifies periodically the elevation angle from $\theta_{\min }=10^{\circ}$ to $\theta_{\max }=40^{\circ}$, as discussed in Section II-D. High signal levels measured at very close interrogation distances $(<50 \mathrm{~cm})$ are due to the electromagnetic coupling between $T x$ and $R x$ antennas of the radar. A range focusing algorithm is now proposed in order to select only the region of the image which may contain the radar echoes of the vine plants (step $(v)$ in Fig 8):

- We remove the 30 first range bins of the image and the last 5 range bins. Therefore, the coupling between the $T x$ and $R x$ antennas as well as eventual radar echoes from other vine rows are not suppressed from the radar image;

- Radar echo levels lower than the pre-defined threshold $T h r$ are replaced by the value $\overline{M_{T D}}+\delta_{t h r}$, where $\overline{M_{T D}}$ is the mean value of echo level in the radar image $M_{T D}$ and $\delta_{t h r}=5 \mathrm{~dB}$;

- Next, a Canny edge filter [19] is applied with a Gaussian filter of standard deviation $\sigma_{\text {Canny }}=10$. The resulting filtered matrix is a binary image illustrated in Fig 9b; 


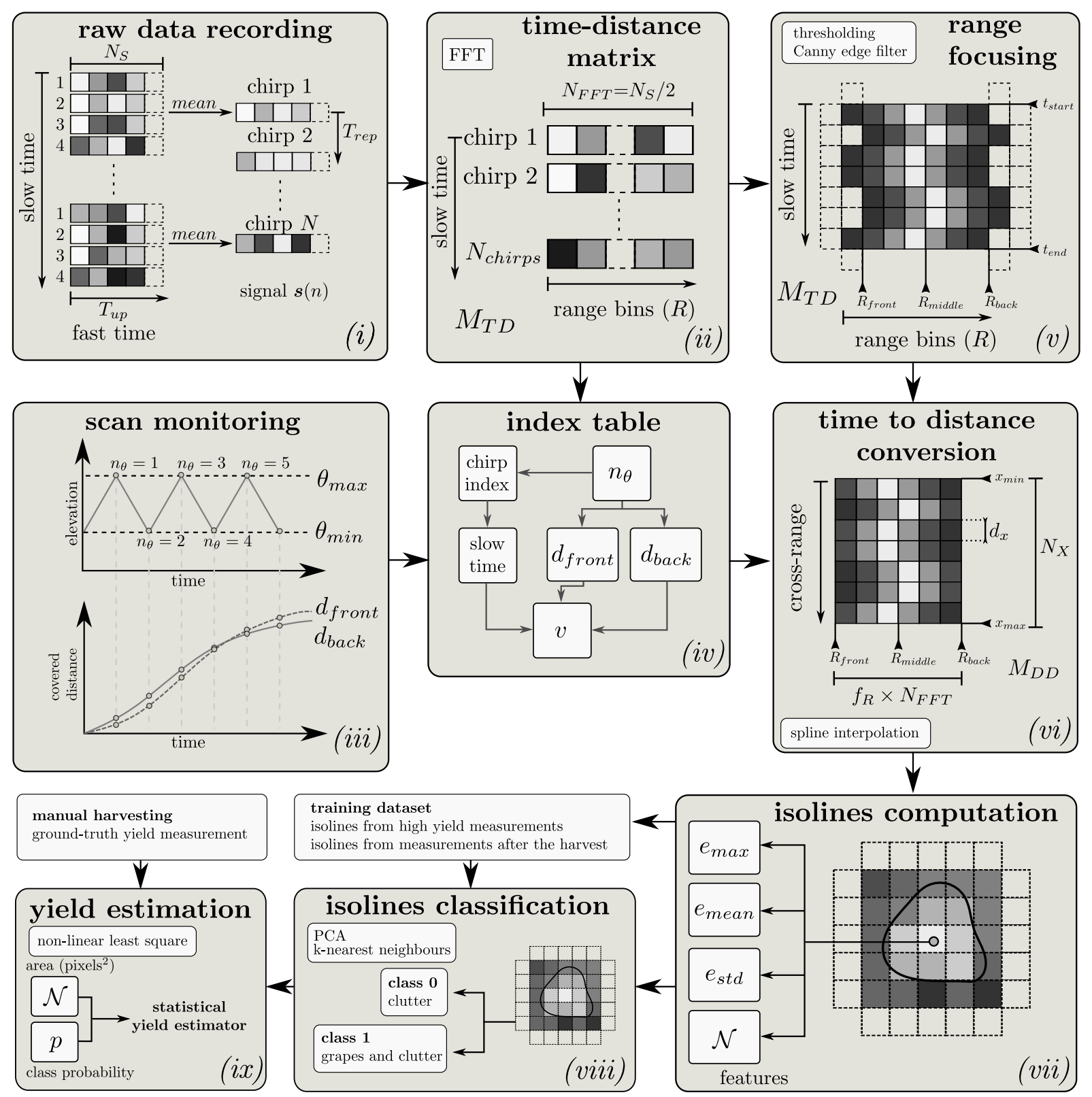

Fig. 8. Flowchart of the dynamic beamscanning and signal processing steps leading to the yield estimation.

- For each range bin, the number of white pixels are computed within a sliding window of 5 range bins. The mean front range of the vine row, denoted by $R_{\text {front }}$, is the lowest range which includes the highest number of white pixels. The mean back range $R_{b a c k}$ of the vine row is the largest range which includes the highest number of white pixels. The mean range of the vine row is $R_{\text {middle }}=\frac{R_{\text {front }}+R_{\text {back }}}{2} . R_{\text {front }}, R_{\text {middle }}$ and $R_{\text {back }}$ are indicated by dashed lines respectively in magenta, cyan and yellow colors in Fig 9b.

From the described steps, radar image is obtained for radarto-vine plants distances ranging from $R_{\text {front }}$ to $R_{\text {back }}$ and from which the yield will be estimated. Moreover, for all radar measurements made in 2019 and 2020, the estimated average distance $R_{\text {middle }}$ is of $1.5 \mathrm{~m} \pm 10 \mathrm{~cm}$. Values of $\delta_{t h r}$ and $\sigma_{\text {Canny }}$ may be chosen by performing a parametric analysis.
Lets define $\sigma_{R_{\text {front }}}$ and $\sigma_{R_{\text {back }}}$ the standard deviations of respectively $R_{\text {front }}$ and $R_{\text {back }}$ estimated along a given vine row. $\sigma_{R_{\text {front }}}$ and $\sigma_{R_{\text {back }}}$ are plotted in Fig $10 \mathrm{a}$ and $10 \mathrm{~b}$ as a function of $\delta_{t h r}$ and $\sigma_{\text {Canny }}$ along all furrows at date 09-072020. Large variations of $\sigma_{R_{\text {front }}}$ and $\sigma_{R_{\text {back }}}$ are observed for $\sigma_{\text {Canny }}<5$. By choosing $\delta_{t h r}=5 \mathrm{~dB}$ and $\sigma_{\text {Canny }}=10$, $R_{\text {front }}$ and $R_{\text {back }}$ are estimated with variations lower than $10 \mathrm{~cm}$ between groups of vineplants.

\section{B. Time-Distance to Distance-Distance Conversion}

As mentioned in Section II-D, the speed $v$ of the rover is not constant during the radar measurement. It is illustrated in Fig 11a where $v$ is plotted as a function of the measurement duration $T=T_{\text {rep }} \times N_{\text {chirps }}$ obtained in 2019 (red crosses) and 2020 (blue crosses). It can be observed that the speed estimated 

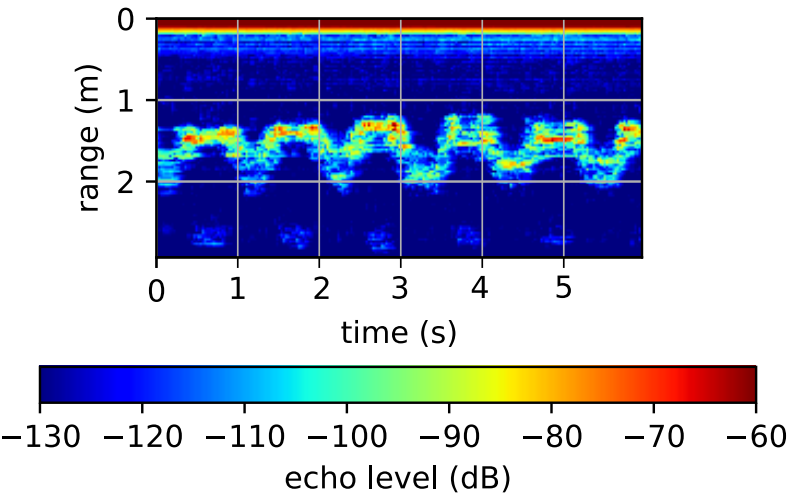

(a)

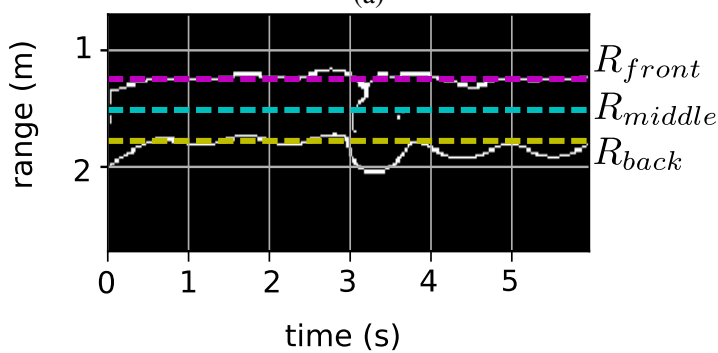

(b)

Fig. 9. (a) Time-distance radar image obtained from measuring a group of vine plants during 5.9s (R10 - Mourvèdre variety - part of group 5 - 09-072020) (b) Filtered radar image after applying a Canny edge filter. Magenta, yellow and cyan dashed lines represent respectively the estimated front range $R_{\text {front }}$, back range $R_{\text {back }}$ and mean range $R_{\text {middle }}$ of the vine row.

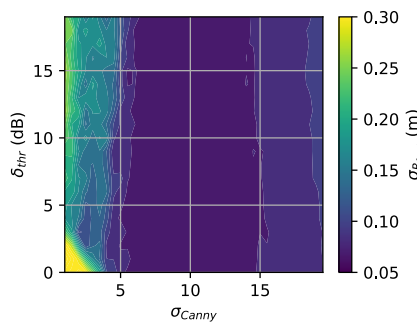

(a)

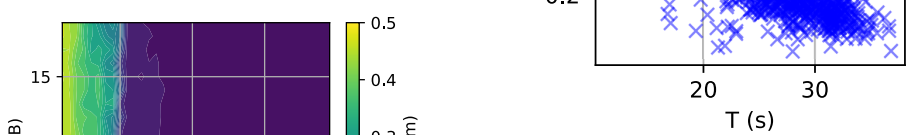

(a) (b)

Fig. 10. Standard deviations of (a) $R_{\text {front }}$ and (b) $R_{\text {back }}$ estimated along all furrows at date 09-07-2020 as a function of $\delta_{t h r}$ and $\sigma_{\text {Canny }}$.

in 2019 and 2020 varies differently. The $\frac{v}{T}$ slope is higher in 2019, and radar data obtained in 2019 and 2020 present different time-speed characteristics. Consequently, either the speed of the rover or the repetition time is poorly estimated. Since the repetition time is controlled electronically with the same standard deviation of $\pm 0.9 \mathrm{~ms}$ in 2019 and 2020, the most likely reason is that wheel encoders estimate the real covered distance with poor accuracy. For example, wheels adhesion may depend on the speed of the rover and it might be overestimated in 2019. Moreover $v$ and $T$ are strongly correlated (the Pearson correlation coefficient is actually of -0.92). Consequently, it may impact the yield estimation if this estimation is performed on the time-distance radar image $M_{T D}$ described in Section III-A. Indeed, the yield estimation reported in Section III.E is based on the number of pixels. The estimation error increases when pixels do not represent the same surface. For low rover speeds, the yield may be over-

estimated and inversely, for high rover speeds, the yield may be underestimated. To overcome this issue, the time-distance radar image $M_{T D}$ is converted into a distance-distance radar image $M_{D D}$ composed of pixels of size $d \times d_{x}$ where $d_{x}$ is the cross-range resolution (step (vi) in Fig 8). The conversion is made using a spline interpolation function [20] with a is $f_{x}=\frac{v \cdot T_{r e p}}{d_{x}}$ with a chosen cross-range resolution $d_{x}=1 \mathrm{~cm}$. The range zoom factor is $f_{R}=2$. The converted radar image $M_{D D}$ is therefore a matrix of dimensions $N_{X} \times N_{F F T} \cdot f_{R}$, with $N_{X}=\operatorname{int}\left(\frac{d_{\text {back }}+d_{\text {front }}}{2 . d_{x}}\right)$, where int is the entire function. In Fig $11 \mathrm{~b}$ the speed of the rover is plotted as a function of the number of pixels $N_{X}$ for measurements obtained in 2019 (red crosses) and in 2020 (blue crosses). As desired, $N_{X}$ and $v$ are now uncorrelated parameters (the Pearson correlation coefficient is of 0.18 ). We note that the time-speed characteristics of 2019 and 2020 data offer slightly different $N_{X}$ values: $N_{X}$ has a mean value of $578 \pm 27$ in 2019 and of $558 \pm 64$ in 2020 . We may expect an overestimation of the yield in 2019 (compared with the estimation obtained in 2020).

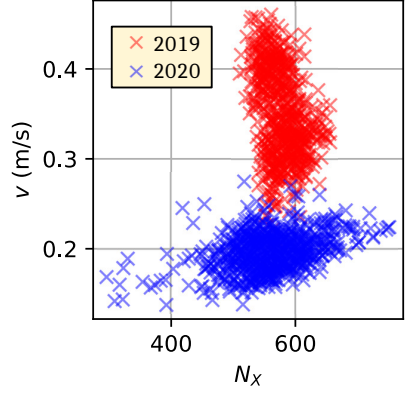

(b)
Fig. 11. (a) Speed of the rover $v$ as a function of the measurement time $T$ from the time-distance radar image $M_{T D}$. (b) Speed of the rover $v$ as a function of the number of pixels $N_{X}$ from the distance-distance radar image $M_{D D}$ derived from the time-to-distance conversion.

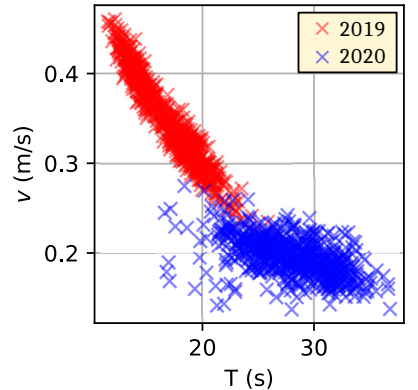

\section{Radar Echoes Classification}

To analyze each radar echo, an algorithm based on the marching square algorithm is applied [21]. The segmentation is described in details in [15] and represented by step (vii) in Fig 8. It generates isolines with an adaptative threshold. Here are the main parameters used for the segmentation: the minimal threshold of echo level is $-110 \mathrm{~dB}$; the minimal surface enclosed by an isoline is $4 \mathrm{px}^{2}$; the maximal number of local peaks of echo level enclosed by an isoline is 4 . An example of segmentation applied to the matrix $M_{D D}$ (see Section III-B) is shown in Fig 12 (R10 - Mourvèdre variety - group 5 - 0907-2020). The four following features are extracted from the segmented radar echoes :

- the maximum echo level $e_{\max }$ of the radar echo. It is indicated by blue to red colors in Fig 12;

- the mean echo level $e_{\text {mean }}$ of the radar echo;

- the standard deviation echo level $e_{s t d}$ of the radar echo;

- the number $\mathcal{N}$ of pixels of the radar echo. The area of one pixel is $\frac{d}{f_{R}} \times d_{x}=1.15 \mathrm{~cm}^{2}$. 


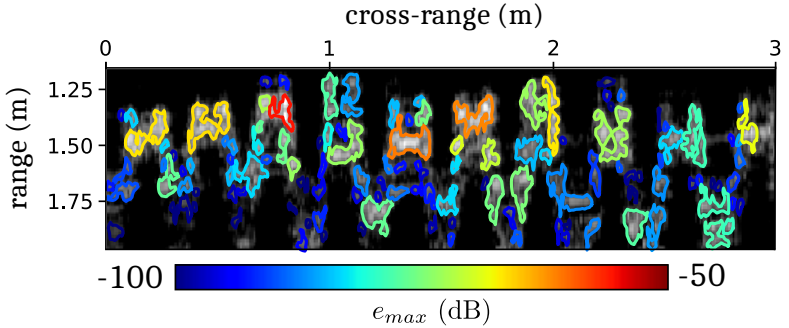

Fig. 12. Radar image $M_{D D}$ (R10 - Mourvèdre variety - part of group 5 09-07-2020). Coloured lines represent isolines used for the segmentation of radar echoes. Blue $(-100 \mathrm{~dB})$ to red $(-60 \mathrm{~dB})$ colors indicate the value of the extracted feature $e_{\max }$

Note that these four features were previously defined in [12] to estimate the yield from using stationary radars. To mitigate the clutter, the classification of radar echoes from the four features $e_{\text {max }}, e_{\text {mean }}, e_{s t d}$ and $\mathcal{N}$ is performed. To reduce the number of features and decrease the computation time, we apply the PCA (Principal Component Analysis), which consists of computing four orthogonal components modeling the set of data is applied. The obtained relative variances of the four computed orthogonal components $p_{1}, p_{2}, p_{3}$ and $p_{4}$ are respectively $75.3 \%, 17,1 \%, 7.0 \%$ and $0.6 \%$. Most of the data $(75.3 \%)$ is represented by the first component $p_{1}$ of the orthogonal basis. Only $0.6 \%$ of the data is represented by the fourth component. Consequenlty we reduce here the dimensions of the data to three principal orthogonal components $p_{1}$, $p_{2}$ and $p_{3}$.

We consider for the classification two classes (step (viii) in Fig 8). Class 0 is called clutter and represents radar echoes from unwanted electromagnetic scatterers (wood, leaves, metallic wires...). Class 1 is called grapes and clutter and represents radar echoes of grapes including the abovementioned clutter. The classification is built from the KNN (K-nearest neighbors) method on the segmented radar echoes with $K=40$. The value of $K$ will be discussed later in this Section. Note that scales, PCA and classifications described here are performed using algorithms reported in [22] with the following training data:

- For class 0 (clutter): all segmented radar echoes from the date 09-30-2020 (after the harvest) of vine rows $R 3, R 6$, $R 7, R 9, R 10$ and $R 12$. In this case, there is no grapes in the vine plants;

- For class 1 (grapes and clutter): segmented radar echoes from the dates 08-17-2020, 08-31-2020 and 07-09-2020 of vine rows $R 3, R 6, R 7, R 9, R 10$ and $R 12$. To mitigate the clutter, radar echoes ranging from $R_{\text {front }}$ to $R_{\text {middle }}$ are chosen (that is, at distances for which grapes may be present in the scanned vine plants). Moreover, only groups of vine plants for which the yield is at least of $15 \mathrm{~kg}$ are processed.

Testing data are identical to training data, but with different vine rows $(R 4, R 5, R 8$, and $R 11)$. Confusion matrices of training and testing data are displayed in Table IV for $H H$ and $V V$ polarization configurations. For $H H$ polarization configuration, the classification score is $76.7 \%$ for the training data (17103 radar echoes), and $77.3 \%$ for the testing data
(8855 radar echoes). The most relevant result is that $62.7 \%$ of the actual training data of class 1 (i.e. grapes and clutter) are true positive ( $71.5 \%$ for the testing data). This means that more that $60 \%$ of segmented radar echoes in presence of grapes offer features different that from segmented radar echoes of clutter only. In comparison, the percentage of true positive in $V V$ polarization configuration drops down to $29.0 \%$ for the training data (27.4\% for the test data). Our first hypothesis of this effect is that the clutter may impact more significantly the radar echoes in $V V$ polarization configuration than in $H H$ polarization configuration. This result may be explained by the strong contribution to the V-polarized backscattered electromagnetic field of vertically oriented reflective objects in the vineyard, such as, trunks of vine plants or metallic stakes. These results should be confirmed in the future with more measurement data obtained from various polarization configurations. Consequently, only radar data in $H H$ polarization configuration will be used for the yield estimation. It includes measurements obtained in 2019 and 2020 (see Table II).

The $K N N$ classifier is tested in $H H$ polarization configuration for various values of $K$. Training and testing data are those used in the previous paragraph. The error rate of the classification is displayed as a function of $K$ in Fig 13. The asymptotic behavior, reported in [23], provides the error rate of $22 \%$. By choosing $K=40$, the error rate is close to the asymptotic value without excessive computation time.

TABLE IV

CONFUSION MATRICES IN HH AND VV POLARIZATION CONFIGURATIONS

\begin{tabular}{|c|c|c|c|c|}
\hline \multirow[t]{2}{*}{ HH } & \multicolumn{2}{|c|}{$\begin{array}{l}\text { training } \\
\text { predicted }\end{array}$} & \multicolumn{2}{|c|}{$\begin{array}{l}\text { testing } \\
\text { predicted }\end{array}$} \\
\hline & 0 & 1 & 0 & 1 \\
\hline 0 & $\begin{array}{c}8454 \\
(87.4 \%)\end{array}$ & $\begin{array}{c}1208 \\
(12.5 \%)\end{array}$ & $\begin{array}{c}5113 \\
(79.4 \%)\end{array}$ & $\begin{array}{c}1320 \\
(20.5 \%)\end{array}$ \\
\hline 1 & $\begin{array}{c}2775 \\
(37.2 \%)\end{array}$ & $\begin{array}{c}4666 \\
(62.7 \%)\end{array}$ & $\begin{array}{c}689 \\
(28.4 \%)\end{array}$ & $\begin{array}{c}1733 \\
(71.5 \%)\end{array}$ \\
\hline
\end{tabular}

score: 76,7\% (training); 77,3\% (testing)

number of data: 17103 (training); 8855 (testing)

\begin{tabular}{c|c|c|c|c|c|}
\multicolumn{2}{c}{ VV } & \multicolumn{2}{c}{$\begin{array}{c}\text { training } \\
\text { predicted }\end{array}$} & \multicolumn{2}{c}{ testing } \\
predicted
\end{tabular}

score: $64,7 \%$ (training); $69,2 \%$ (testing)

number of data: 17460 (training); 9304 (testing)

\section{Features Analysis}

The values of the four features $\mathcal{N}, e_{\text {max }}, e_{\text {mean }}$ and $e_{s t d}$ are now compared for the Class 0 (clutter) and Class 1 (grapes and clutter). In Fig 14 are displayed the distributions $\phi$ of these features for true positives (blue triangles) and true negatives (red triangles) of training and testing data. As observed, $\phi_{\mathcal{N}}$ has higher values for the Class 1 grapes and clutter and for a number of pixels from 8 to 12 pixels (that is, from 9.2 


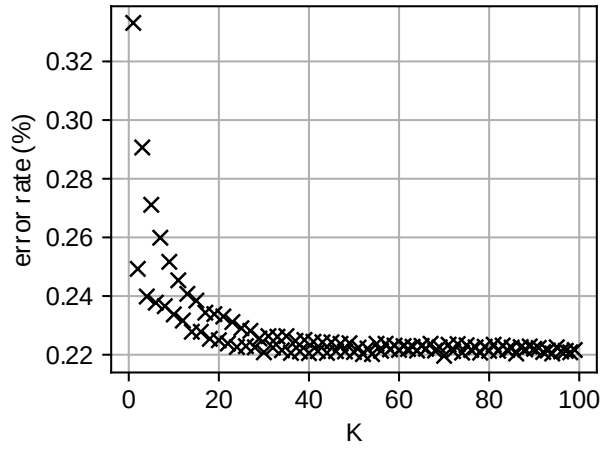

Fig. 13. Error rate of the $K N N$ classifier as a function of $K$ value for the $H H$ polarization configuration.

to $13.8 \mathrm{~cm}^{2}$ ). The mean value difference of $\phi_{\mathcal{N}}$ between true positives and true negatives is 0.8 pixels (i.e. $1.0 \mathrm{~cm}^{2}$ ). For this class, the mean values of distributions $\phi_{e_{\text {max }}}, \phi_{e_{\text {mean }}}$ and $\phi_{e_{s t d}}$ are higher than those for the Class 0 grapes and clutter. The mean value differences of $\phi_{e_{\text {max }}}, \phi_{e_{\text {mean }}}$ and $\phi_{e_{s t d}}$ between true positives and true negatives are respectively $13.0 \mathrm{~dB}$, $10.6 \mathrm{~dB}$ and $1.0 \mathrm{~dB}$. This result was expected as grapes contain water, they strongly backscatter the incident electromagnetic field and consequently, the radar echo level is higher before than after the harvest. As a result, the correlated measured features $\mathcal{N}, e_{\text {max }}, e_{\text {mean }}$ and $e_{s t d}$ increase.
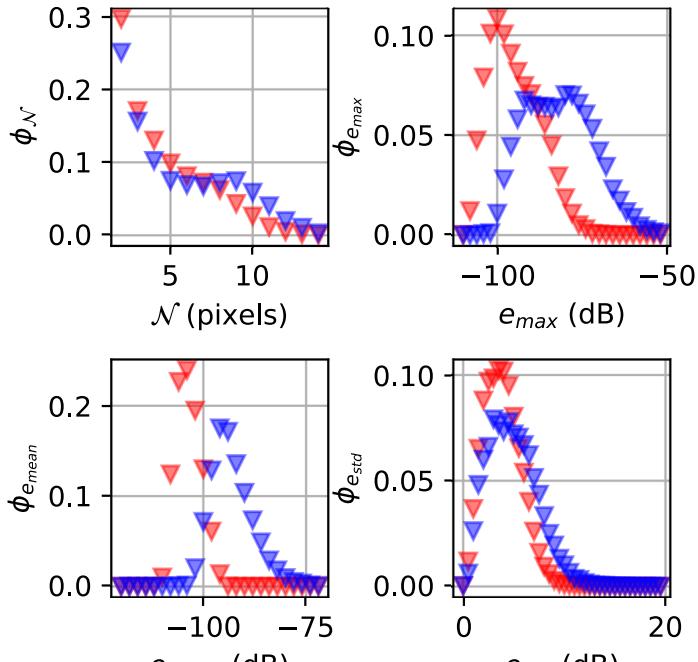

$e_{\text {mean }}(\mathrm{dB})$ $e_{s t d}(\mathrm{~dB})$

$\nabla$ true positives (grapes and clutter) $\nabla$ true negatives (clutter)

Fig. 14. Distributions $\phi$ of the four features $\mathcal{N}, e_{\max }, e_{\text {mean }}$ and $e_{\text {std }}$ for true positives (grapes and clutter; blue triangles) and true negatives (clutter; red triangles) radar echoes of training and testing dataset.

Another analysis consists of estimating the range $R$ of each radar echo level. Since it is composed of several pixels, the location of the radar echo is defined as the barycenter range coordinate of the isoline that segments the radar echo. The distribution $\phi_{R}$ of the computed range is displayed in Fig 15a for true positives (blue triangles) and true negatives (red triangles) of training and testing data. We observe a shift between the two distributions: the mean range of radar echoes is $1.52 \mathrm{~m}$ for Class 1 and $1.66 \mathrm{~m}$ for Class 0 . The reason is illustrated in Fig 15b where isolines are displayed for the $M_{D D}$ radar image (see Section III-C) before and after the harvest (09-07-2020). Red to blue colored isolines indicate the predicted probability for a radar echo to belong to the Class 1 . Thus, radar echoes segmented by red colored isolines belong to Class 1 with a probability of $0 \%$, while radar echoes segmented by blue colored isolines belong to Class 1 with a probability of $100 \%$. Before the harvest, most of the radar echoes in Class 1 are at ranges for which highest echo levels are found. After the harvest, the number of radar echoes in Class 1 decreases and is more evenly distributed between $R_{\text {front }}$ and $R_{\text {back }}$.

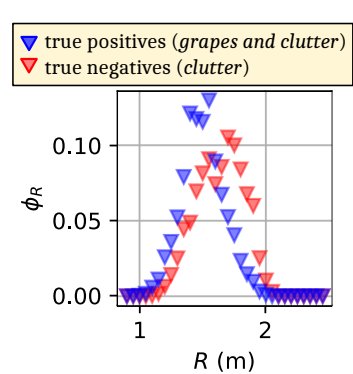

(a)

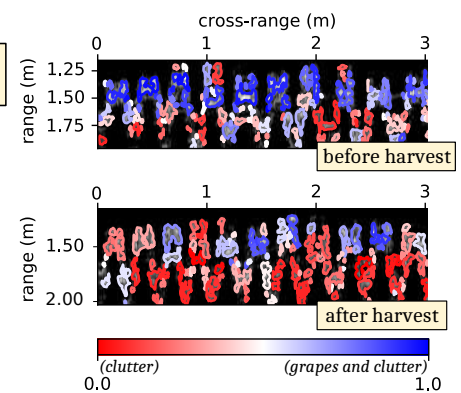

(b)
Fig. 15. (a) Distribution $\phi_{R}$ of the range $R$ for true positives (grapes and clutter; blue triangles) and true negatives (clutter; red triangles) radar echoes of training and testing dataset. (b) Segmented radar echoes of the radar image $M_{D D}$ (R10 - Mourvèdre variety - part of group 5) before the harvest (09-072020) and after the harvest (09-30-2020). Red (0) to blue (1) colors indicate the predicted probability for a radar echo to belong to the class grapes and clutter.

\section{E. Definitions for the Estimation of the Yield}

The classification proposed in Section III-C is used to build an estimator of the yield from radar images in $H H$ polarization configuration (step $(i x)$ in Fig 8). We define the statistical estimator of the yield as follows:

$$
\text { est }_{0}=a \times\left(\sum_{m=1}^{M} p_{m} \times \mathcal{N}_{m}\right)^{b}
$$

where $\mathcal{N}_{m}$ denotes the number of pixels of the $m^{\text {th }}$ radar echo, and $p_{m}$ is the probability for the $m^{\text {th }}$ radar echo to belong to the Class 1 (grapes and clutter). $M$ designates the total number of radar echoes in the Class 1 (i.e, for $p_{m}>0.5$ ), and $a$ and $b$ are two positive and real numbers. According to the definition of equation (7), we expect that the yield increases with the number of pixels of the Class 1 . Moreover, if all radar echoes belong to the Class 0 (clutter), the estimated yield should be zero. Values of $a$ and $b$ are computed with the non-linear least square method [24] for groups of vine plants with yield of at least $12 \mathrm{~kg}$ measured at the following dates: 09-12-2019, 09-07-2020 and 08-31-2020. The yield estimator is defined at these dates for a maximum variability since low and high speeds are used for the radar data obtained in 2019 and 2020, respectively. We obtain $a=8.6 \times 10^{-2} \mathrm{~kg}$.pixels ${ }^{-b}$ with $b=8.8 \times 10^{-1}$. The statistical estimator $e^{2} t_{0}$ is plotted as 
a function of the measured (ground truth) yield in Fig 16a and 16b at the following dates: 09-12-2019 (red crosses), 0907-2020 (blue crosses) and 08-31-2020 (green crosses). Each cross represents the combined summation of yields for several groups of vine plants, such as the smallest yields are measured from single groups of vine plants while the largest yield is the summation of all measured yields. We observe different estimations: the yield estimations obtained in 09-07-2020 and 08-31-2020 are found very close, while they differ in 2019. To evaluate the validity of the proposed estimator, the relative error of yield estimation is defined as follows:

$$
\varepsilon=\frac{\left|y_{\text {est }}-y_{\text {meas }}\right|}{y_{\text {meas }}}
$$

where $y_{\text {est }}$ and $y_{\text {meas }}$ denote respectively the estimated and measured (ground truth) yields. The relative error is displayed in Fig 16c and 16d. Error $\varepsilon$ in 09-07-2020 (blue crosses) and 08-31-2020 (green crosses) are identical and tend to $25 \%$ as the measured yield increases. In date 09-12-2019 (red crosses), $\varepsilon$ is smaller than the symbolic limit of $10 \%$ (in black dashed line). These results demonstrate that the statistical estimator $e t_{0}$ for the yield estimation defined in Equation (7) provides inaccurate results for measurements performed both in 2019 and 2020. One possible cause of this inaccuracy is the speedtime characteristics difference between 2019 and 2020 (see Section III-B). To overcome this issue, next paragraph reports a solution for enhancing the accuracy of the yield estimation from radar data obtained with different rover's speeds.

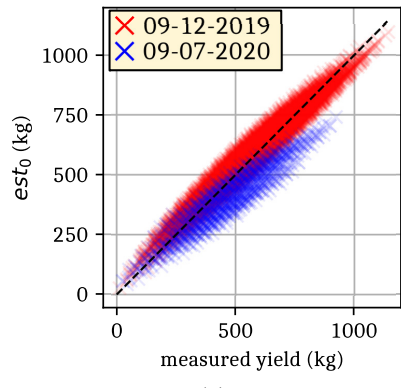

(a)

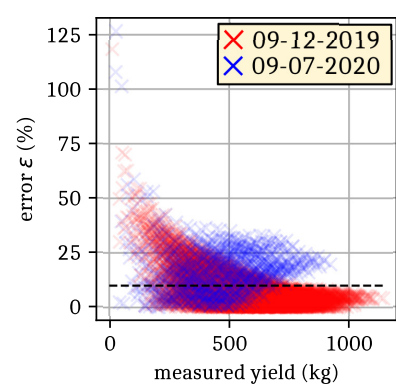

(c)

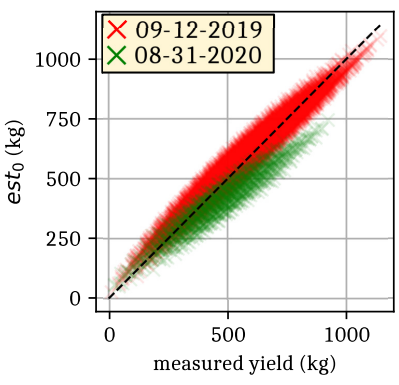

(b)

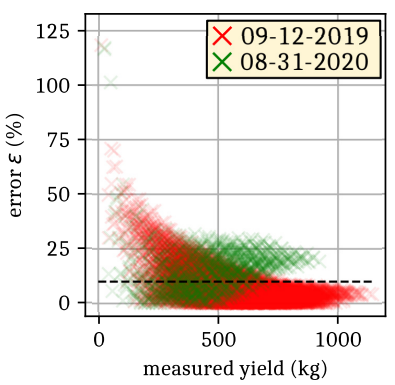

(d)
Fig. 16. (a)-(b) Estimated yield $e^{2} t_{0}$ and (c)-(d) relative error $\varepsilon$ as a function of the measured yield for combined summation of yields $(>12 \mathrm{~kg})$ of several groups of vine plants at dates 09-12-2019 (red crosses), 09-07-2020 (blue crosses) and 08-31-2020 (green crosses).

According to our previous works [15], the presence or absence of fruits (grapes or apples) in the scanned scene may have an impact on the average size of segmented radar echoes. In presence of grapes, the so-called condensation of the segmented radar echoes (or set of isolines) generates an increase of the pixel number of the segmented radar echoes as the total number of segmented radar echoes decreases. Inversely, a fragmentation of the segmented radar echoes is observed in absence of grapes. These observations may be advantageously used here to accurately estimate the yield for different speeds of the rover. For this purpose, the mean number $\overline{\mathcal{N}}$ of pixels of segmented radar echoes of class grapes and clutter is defined by the following expression:

$$
\overline{\mathcal{N}}=\frac{1}{M} \sum_{m=1}^{M} \mathcal{N}_{m}
$$

From equations (7) and (9), a new second statistical estimator of the yield is defined as follows:

$$
\begin{array}{ll} 
& e t_{1}=\xi_{c, d}(\overline{\mathcal{N}}) \times \text { est }_{0} \\
\text { with } & \xi_{c, d}(x)=\frac{1}{2}(1+\tanh (c \times x+d))
\end{array}
$$

where $c$ and $d$ are real numbers and such that the function $\xi_{c, d}$ is defined in $\Re$ and $0 \leq \xi_{c, d}(x) \leq 1$ for all $x$ values. Since $e t_{1}$ depends also on $e s t_{0}$, the values of $a, b, c$ and $d$ can be computed from the non-linear least square method with the data used in Section III-E. We obtain $a=5.9 \times 10^{-2}$ kg.pixels ${ }^{-b}, b=9.8 \times 10^{-1}, c=0.7$ pixels $^{-1}$ and $d=-3.6$. Note that $b$ is close to 1 and est $(M)$ is considered linear. The resulting yield estimation est $_{1}$ is plotted in Fig 17a and Fig $17 \mathrm{~b}$ as a function of the measured (ground truth) yield at the following dates: 09-12-2019 (red crosses), 09-07-2020 (blue crosses) and 08-31-2020 (green crosses). In comparison with est $t_{0}$, both 2019 and 2020 data fit better the ground-truth value of the yield. The relative error $\varepsilon$ is plotted in Fig 17c and Fig $17 \mathrm{~d}$ : it is smaller than $10 \%$ (black dashed line) for a measured yield of $780 \mathrm{~kg}$ or more. We conclude that the contribution of the function $\xi_{c, d}$ improves significantly the accuracy of the yield estimation for different speeds of the rover. To understand its role , $\xi_{c, d}$ is plotted in Fig 18 as a function of $\overline{\mathcal{N}}$ for the computed values $c=0.7$ pixels $^{-1}$ and $d=-3.6$. Since $c>0, \xi_{c, d}$ is an increasing function. For higher values of $\overline{\mathcal{N}}$, that is, for the condensation of the set of segmented radar echoes, both $\xi_{c, d}$ and $e s t_{1}$ increase according to (10).

\section{F. Yield Estimation Results}

Yield estimator est $_{1}$ computed in Section III-E is first validated on radar data for which the yield per group is of $12 \mathrm{~kg}$ or more. The estimated yield and relative error are displayed in Table $\mathrm{V}$ for all measurements. We observe that one month before the harvest (starting at 8-27-2019 and 8-17-2020), the relative error $\varepsilon$ does not exceed $5 \%$ for various meteorological conditions (such as rain at date 8-27-2019 or humidity at 09$12-2019)$. In 2020 , the estimated yield increases from $548.0 \mathrm{~kg}$ $(40.6 \%)$ to $890.4 \mathrm{~kg}(2.1 \%)$. As explained in Section II-A, this result was expected since the volume of grapes increases significantly from July to August. Note that the yield is also estimated after the harvest (09-23-2019 and 09-30-2020). The slight overestimation of the yield at date 31-08-2020 may be explained by losses of grapes observed between 08-312020 and 09-07-2020. We assume that these unexpected losses 


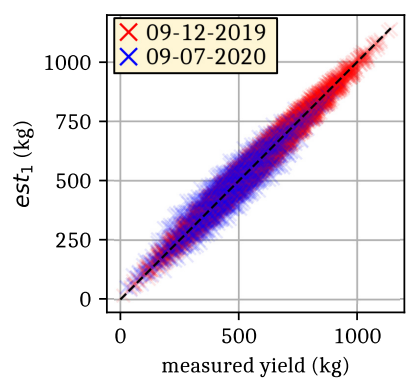

(a)

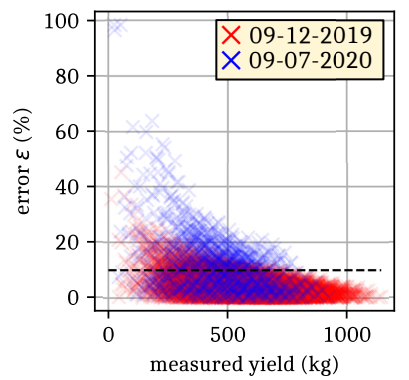

(c)

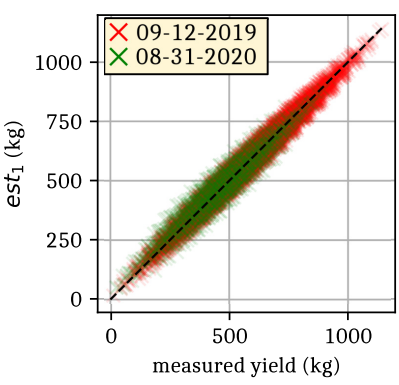

(b)

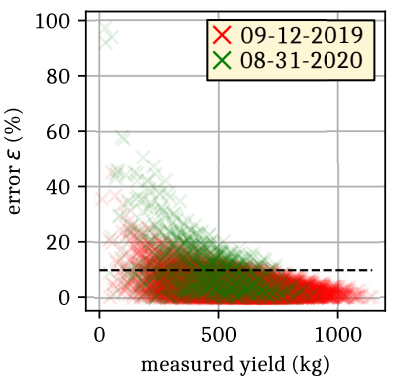

(d)
Fig. 17. (a)-(b) Estimated yield $e^{2} t_{1}$ and (c)-(d) relative error $\varepsilon$ as a function of the measured yield for combined summation of yields $(>12 \mathrm{~kg})$ of several groups of vine plants at the dates 09-12-2019 (red crosses), 09-07-2020 (blue crosses) and 08-31-2020 (green crosses).

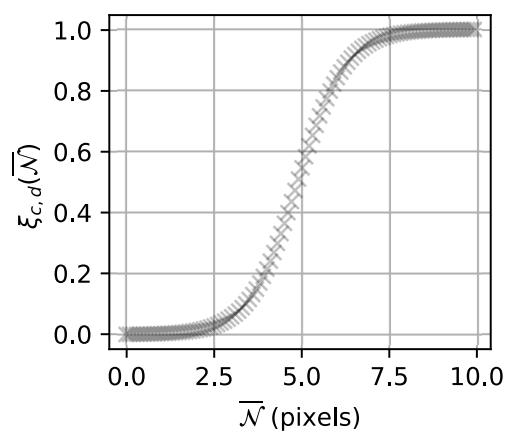

Fig. 18. $\xi_{c, d}$ as a function of $\overline{\mathcal{N}}$ for the computed values $c=0.7$ pixels $^{-1}$ and $d=-3.6$.

were caused by animal or human interventions. At 09-302020 , the estimated yield is of $280.9 \mathrm{~kg}$ for 46 groups of vine plants $(6.1 \mathrm{~kg}$ per group). This value is the minimal detectable yield per group of 6 vine plants with the used beamscanning. Below this threshold, grapes and clutter are not easily distinguishable. At 09-23-2019, the estimated yield is abnormally high (1121.7kg for 66 groups of vine plants) with a minimal detectable yield per group of 6 vine plants of $17.0 \mathrm{~kg}$. A possible explanation of this overestimation is proposed in Section IV-F.

The yield estimator est 1 is also computed for all yield values and reported in Table VI. We note that the error on the total yield estimation does not change significantly but as it will be shown in Section IV-A, the variation of the relative error is higher when the yield estimation is computed for all yield values. The estimated yield after the harvest in 2020 is of $377.9 \mathrm{~kg}$ for 64 groups of vine plants. The minimal detectable yield is then $5.9 \mathrm{~kg}$ per group of 6 vine plants.

TABLE V

ESTIMATED YIELD AND RELATIVE ERROR FROM MEASUREMENTS PERFORMED IN 2019 AND 2020 AND YIELD PER GROUP > 12KG.

\begin{tabular}{|c|c|c|c|}
\hline date $^{a}$ & measured (kg) & estimated (kg) & $\varepsilon(\%)$ \\
\hline $07-30-2019$ & 711.8 & 773.9 & 8.7 \\
\hline 08-08-2019 & 711.8 & 722.7 & 1.5 \\
\hline $08-22-2019$ & 132.0 & 123.3 & 6.6 \\
\hline 08-27-2019 & 1142.5 & 1184.4 & 3.7 \\
\hline 09-03-2019 & 1142.5 & 1164.7 & 1.9 \\
\hline 09-12-2019* & 1142.5 & 1168.6 & 2.3 \\
\hline 09-23-2019 & 0 & 1199.0 & - \\
\hline 07-01-2020 & 922.4 & 548.0 & 40.6 \\
\hline 07-08-2020 & 922.4 & 739.5 & 19.8 \\
\hline 07-13-2020 & 922.4 & 791.1 & 14.2 \\
\hline $07-22-2020$ & 922.4 & 796.9 & 13.6 \\
\hline $08-17-2020^{\dagger}$ & 922.4 & 898.5 & 2.6 \\
\hline $08-31-2020 \dagger *$ & 922.4 & 942.4 & 2.2 \\
\hline 09-07-2020 ${ }^{\dagger} *$ & 922.4 & 890.4 & 3.5 \\
\hline 09-30-2020 ${ }^{\dagger}$ & 0 & 280.9 & - \\
\hline \multicolumn{4}{|c|}{$\begin{array}{l}\text { estimator est } \text { is }_{1} \text { computed with } a=5.9 \times 10^{-2} \text { kg.pixels }{ }^{-b} \text {, } \\
b=9.8 \times 10^{-1}, c=0.7 \text { pixels }-1 \text { and } d=-3.6 \\
a: \text { mm-dd-yyyy format } \\
\dagger: \text { training data for yield per group }>15 \mathrm{~kg} \text { and vine rows } R 3, R 6 \text {, } \\
R 7, R 9, R 10 \text { and } R 12 \\
*: \text { data used to compute estimator } \text { est }_{1}\end{array}$} \\
\hline
\end{tabular}

TABLE VI

ESTIMATED YIELD AND RELATIVE ERROR FROM MEASUREMENTS PERFORMED IN 2019 AND 2020 FOR ALL YIELDS

\begin{tabular}{|c|c|c|c|}
\hline date $^{a}$ & measured (kg) & estimated (kg) & $\varepsilon(\%)$ \\
\hline $07-30-2019$ & 897.8 & 1013.5 & 12.9 \\
\hline 08-08-2019 & 897.8 & 945.0 & 5.3 \\
\hline $08-22-2019$ & 200.7 & 279.7 & 39.4 \\
\hline 08-27-2019 & 1469.4 & 1541.6 & 4.9 \\
\hline 09-03-2019 & 1469.4 & 1516.2 & 3.2 \\
\hline $09-12-2019 *$ & 1469.4 & 1511.9 & 2.9 \\
\hline 09-23-2019 & 0 & 1581.2 & - \\
\hline 07-01-2020 & 1232.3 & 732.0 & 40.6 \\
\hline 07-08-2020 & 1232.3 & 1020.8 & 17.2 \\
\hline $07-13-2020$ & 1232.3 & 1098.1 & 10.9 \\
\hline $07-22-2020$ & 1232.3 & 1116.7 & 9.4 \\
\hline $08-17-2020^{\dagger}$ & 1232.3 & 1241.1 & 0.7 \\
\hline $08-31-2020 \dagger *$ & 1232.3 & 1283.8 & 4.2 \\
\hline $09-07-2020 \dagger *$ & 1232.3 & 1240.3 & 0.6 \\
\hline $09-30-2020^{\dagger}$ & 0 & 377.9 & - \\
\hline \multicolumn{4}{|c|}{$\begin{array}{l}\text { estimator est } t_{1} \text { is computed with } a=4.7 \times 10^{-2} \text { kg.pixels }^{-b} \text {, } \\
b=9.7 \times 10^{-1}, c=1.0 \text { pixels } \\
a: \text { mm-dd-yyyy format } \\
\dagger: \text { training data for yield per group }>15 \mathrm{~kg} \text { and vine rows } R 3, R 6 \text {, } \\
R 7, R 9, R 10 \text { and } R 12 \\
*: \text { data used to compute estimator } \text { est }_{1}\end{array}$} \\
\hline
\end{tabular}

\section{Discussion}

\section{A. Comments on the Relative Error of Yield Estimation}

The relative error reported in Section III-F for the total yield does not highlight the relative error $\varepsilon$ at smallest plot scales. In Fig 19a, the estimations provided by est ${ }_{1}$ for high yields (in blue crosses) and for all yields (in red crosses) are reported at the date 09-07-2020. The relative error is also plotted in Fig 19b. In both cases, the relative error decreases when the measured yield increases, that is, when the surface of the beamscanned plot increases. This phenomenon is explained by the average effect that occurs during the 
computation of the estimator est ${ }_{1}$ with the non-linear least square method. Individual groups of vine plants may present higher relative errors due to various environmental conditions (such as different wood shapes, hidden grapes or the variable rover speed), but the relative error converges to an average value when the total number of groups of vine plants increases. As long as $b$ is close to 1 , est $_{1}$ is approximately linearly dependent on the yield (see equation (7)) and the relative error does not exceed $10 \%$ when the surface of the beamscanned plot increases. The function $\xi_{c, d}$ tends to a limit as the surface of the beamscanned plot increases, as this function depends on the average number of pixels of segmented radar echoes $\overline{\mathcal{N}}$ (see equations (9)-(10)).

Moreover, the relative error of the yield estimation is higher when all yields are estimated: the relative error does not exceed 10\% (black dashed line in Fig 19b) when the measured yield is larger than $750 \mathrm{~kg}$. For all yields, the relative error of the estimation does not exceed $10 \%$ when the measured yield is higher than $1100 \mathrm{~kg}$. These results can be explained from the increasing difficulty to distinguish grapes from the clutter for low yield values ( $<12 \mathrm{~kg}$ per group of 6 vine plants). As a result, the standard deviation of the relative error is higher when $e^{2} t_{1}$ is computed for estimating all yields, and the convergence of $\varepsilon$ to its limit is slower. As expected, performing the yield estimation for different scenarios and various environmental conditions increases the relative error of the yield estimation.

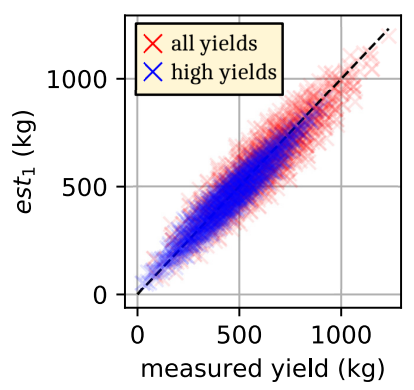

(a)

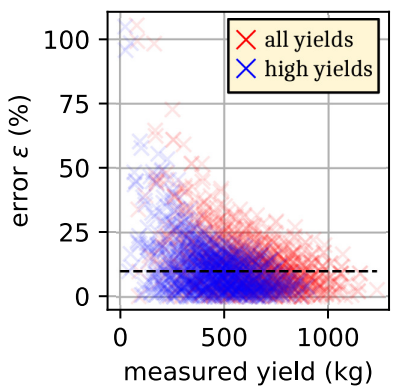

(b)
Fig. 19. (a) Estimated yield $e s t_{1}$ and (b) relative error $\varepsilon$ as a function of the measured yield for combined summation of yields at date 09-07-2020 for all yields (red crosses) and high yields $>12 \mathrm{~kg}$ per group of 6 vine plants (blue crosses) only.

\section{B. Impact of the Rover Speed on the Yield Estimation}

The choice of a rover as a moving platform was a flexible solution to investigate the feasibility and limitations of the yield estimation from a dynamic beamscanning. Future work will consist of performing measurements at various speeds and with different agricultural vehicles, such as quad or straddle tractors. Yield estimation was performed with a rover speed comprised between $0.1 \mathrm{~m} . \mathrm{s}^{-1}$ and $0.5 \mathrm{~m} . \mathrm{s}^{-1}$. With other agricultural vehicles, the speed will increase $(1 \mathrm{~m} / \mathrm{s}$ or more). Thus we may expect an increase of the yield estimation error per scanned surface plot, but compensated by larger beamscanned plot surfaces. To evaluate the impact of the rover speed on the yield estimation error, the cross-range resolution $d_{x}$ defined in Section III-B is degraded on purpose from $d_{x}=1 \mathrm{~cm}$ to $d_{x}=10 \mathrm{~cm}$ and the size of the zoom footprint $\left(f_{x}=\frac{v \cdot T_{r e p}}{d_{x}}, f_{r}\right)$ decreases when $d_{x}$ increases. From a mathematical point of view, degrading the cross-range resolution is equivalent to increase the repetition time $T_{r e p}$ or the rover speed $v$ (however it does not take into account physical impacts such as Doppler effects). An example of radar image $M_{D D}$ (R7Cabernet-Franc variety - group 7 - 09-07-2020) for cross-range resolutions $d_{x}=1 \mathrm{~cm}, d_{x}=5 \mathrm{~cm}$ and $d_{x}=10 \mathrm{~cm}$ are displayed respectively in Fig 20a, 20b and 20c. Computed isolines of radar echoes are also represented by solid color lines. Impact of the increasing cross-range resolution is clearly visible on radar images: it modifies values of features $\mathcal{N}, e_{\text {max }}, e_{\text {mean }}$ and $e_{s t d}$.

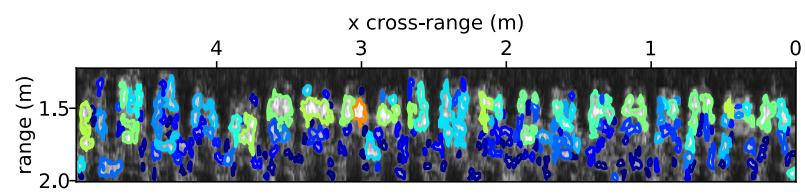

(a)

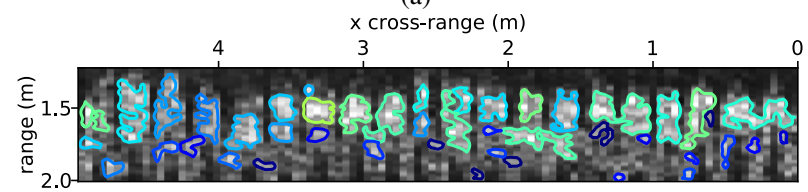

(b)

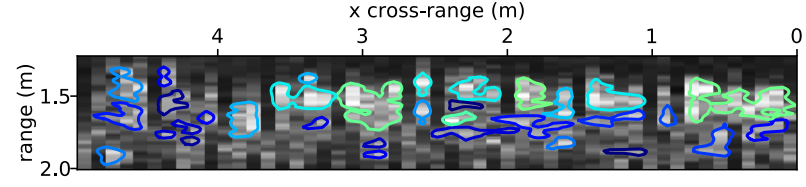

(c)

Fig. 20. Radar image $M_{D D}$ (R7- Cabernet-Franc variety - group 7 - 09-072020) and computed isolines for (a) $d_{x}=1 \mathrm{~cm}$, (b) $d_{x}=5 \mathrm{~cm}$ and (c) $d_{x}=10 \mathrm{~cm}$.

The yield estimator $e^{2} t_{1}$ defined in Section III-F is computed for values of $d_{x}$ varying from $1 \mathrm{~cm}$ to $10 \mathrm{~cm}$. To compare pixels of equivalent surfaces, the estimator is re-built with the updated feature $d_{x} \times f_{r} \times d_{R} \times \mathcal{N}$ instead of the initial feature $\mathcal{N}$ defined in Section III-C. The re-built yield estimator $e t_{1}$ at date 07-09-2020 is plotted on Fig 21a as a function of the cross-range resolution and mean speed of the rover. In this figure, est $t_{1}$ is normalized by the yield estimation obtained for $d_{x}=1 \mathrm{~cm}$ such as $\operatorname{est}_{1, \text { norm }}\left(d_{x}\right)=\frac{\text { est }_{1}\left(d_{x}\right)}{\text { est }_{1}\left(d_{x}=1 \mathrm{~cm}\right)}$. As observed, est $t_{1, \text { norm }}$ decreases when $d_{x}$ increases because of the variations features values $e_{\max }, e_{\text {mean }}$ and $e_{s t d}$. The underestimated yield can be compensated by the proposed linear model (blue solid line on Fig 21a) obtained from a linear regression. Slope of $-0.10 \mathrm{~cm}^{-1}$ and intercept of 1.08 are obtained with a correlation coefficient $R^{2}=0.96$ and a standard error of 0.05 . The underestimated yield may be compensated in the future by adding the speed of the rover as a new feature of the radar echoes classification.

The corrected yield estimator $e s t_{1}$ and its relative error $\epsilon$ are displayed respectively on Fig 21b and Fig 21c as a function of the measured yield. Blue, green and red crosses represent $e s t_{1}$ at date $07-09-2020$ for rover speeds of $0.3 \mathrm{~m} . \mathrm{s}^{-1}, 1.5 \mathrm{~m} . \mathrm{s}^{-1}$ and $3 \mathrm{~m} \cdot \mathrm{s}^{-1}$. As expected the yield estimation error increases with the speed of the rover (i.e. with the resolution of the 
radar image $\left.M_{D D}\right)$. This effect is enlightened by plotting the mean relative error of $\epsilon$ computed over all data at date 07-09-2020 as a function of the cross-range resolution and rover speed on Fig 21d. The mean relative error is lower than $15 \%$ for $d_{x}=1 \mathrm{~cm}$ and reaches values greater than $40 \%$ for $d_{x}=10 \mathrm{~cm}$. Consequently, to obtain equivalent mean relative errors at a higher speed, yield estimations should be performed on larger plot surfaces. These results obtained by degrading the resolution of radar images will be confirmed in the future with measurements at higher speeds.

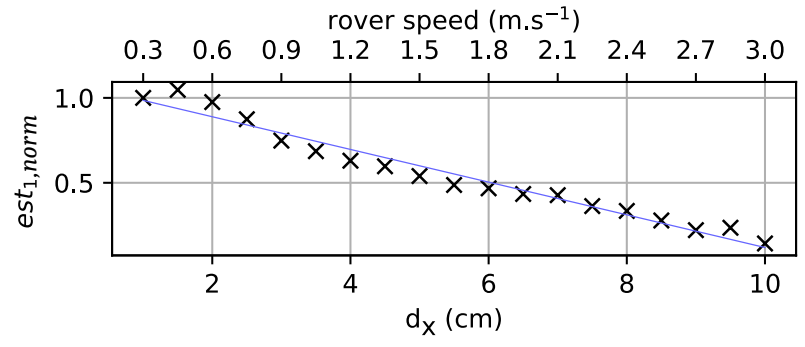

(a)

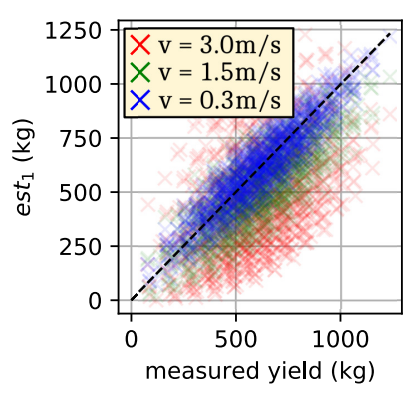

(b)

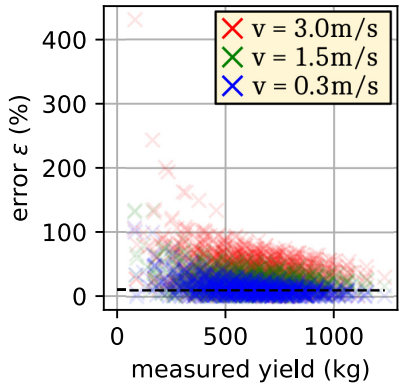

(c) rover speed $\left(\mathrm{m} \cdot \mathrm{s}^{-1}\right)$

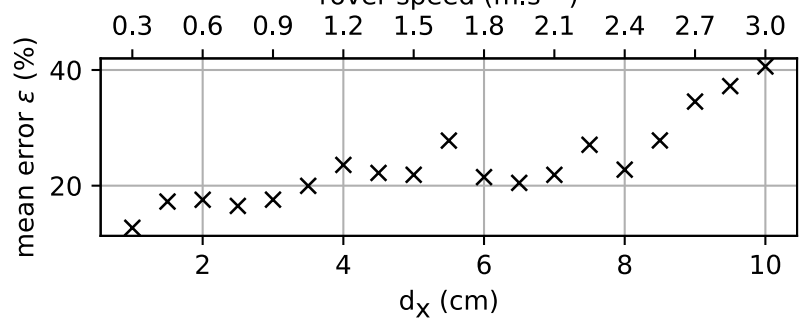

(d)

Fig. 21. (a) Normalized yield estimator est , norm $_{\text {a }}$ as a function of the cross-range resolution $d_{x}$ and mean speed of the rover $v$ at date 09-07-2020. (b) Corrected yield estimator est 1 and (c) relative error $\epsilon$ as a function of the measured yield at date 09-07-2020 for rover speeds of $0.3 \mathrm{~m} . \mathrm{s}^{-1}$ (blue crosses), $1.5 \mathrm{~m} . \mathrm{s}^{-1}$ (green crosses) and $3.0 \mathrm{~m} . \mathrm{s}^{-1}$ (red crosses). (d) Mean relative error $\epsilon$ computed over all measurements at date 07-09-2020 as a function of the cross-range resolution and rover speed.

Up to now, mechanical vibrations and trajectory deviation of the rover (due to ground irregularities) have not been compensated during the yield estimation. When strong deviations are observed, a range compensation algorithm could be applied in order to correct the magnitude of radar echoes. Mechanical vibrations and trajectory deviation should be minimized with the use of agricultural vehicles.

\section{Impact of Meteorological Conditions and Grapes Varieties on the Yield Estimation}

As reported in Table II, measurements were performed for various meteorological conditions. For example, there was a light rain at date 08-27-2019 and it had no major influence on the yield estimation: the estimated yield is $1541 \mathrm{~kg}$ at date 08-27-2019, and $1516 \mathrm{~kg}$ at date 09-03-2019. However, heavy rain may impact the yield estimation: a large amount of water drops on wood or leaves may increase the level of undesirable electromagnetic clutter. Moreover, strong wind may alter the yield estimation by moving the vegetation. Yield estimation with these particular meteorological conditions can be investigated in future studies.

We may also note that the yield has been estimated independently of the grape variety or color (see Table I). It is possible because the yield estimation relies only on the electromagnetic backscattering of the grapes at millimeter-waves. Thus, colors of grapes do not impact the yield estimation from radar data, unlike optical solutions.

\section{Data Size and Computation Time}

The raw data is recorded in a binary file, and the radar echo level of one pixel is a 8 bytes number. By including additional files such as parameters of measurements, the mean data size of a measured group of 6 vine plants with one radar is 16.9ko (216.8Mo for all measurements performed in 2020 with the two radars). The computation time of the different steps leading to the generated isolines per group of 6 vine plants is reported in Table VII. These steps are:

- Step called " $M_{T D}$ corrections" (not detailed in this paper) which includes a range shift correction and redundant data removal that may occur during the communication between the radar and the embedded CPU. This step takes $17.6 \%$ of the computation time;

- Step called "range focus" which is described in Section III-A. This step takes $0.6 \%$ of the computation time;

- Step called "generating $M_{D D}$ " which is detailed in Section III-B. This step takes $0.9 \%$ of the computation time and it depends mainly on chosen values for $d_{x}$ and $f_{r}$;

- Step called "generating isolines" which is described in Section III-C. This step takes $80.9 \%$ of the computation time.

As observed, the computation time is mainly determined from the radar echoes segmentation algorithm. Different parameters can be tuned in order to reduce the computation time, such as the dimensions of $M_{D D}$ or the minimal threshold of echo level. In return, the accuracy of the yield estimation might be impacted.

\section{E. Influence of $\theta_{\min }$ and $\theta_{\max }$ on the Yield Estimation}

We note that $\theta_{\min }$ and $\theta_{\max }$ have different values at the dates 07-30-2019 and 08-08-2019 $\left(0^{\circ}\right.$ and $10^{\circ}$, see Table II). The impact of this $10^{\circ}$ elevation shift can be evaluated by comparing yield estimations for high yield values (Table V) and all yield values (Table VI). For high yield values, the 
TABLE VII

Mean Computation Time of the Main Processing Steps Per GROUP OF 6 VINE PLANTS

\begin{tabular}{|c|c|c|}
\hline steps & $\begin{array}{l}\text { computation } \\
\text { time }(\mathbf{m s})^{a}\end{array}$ & $\begin{array}{l}\text { computation } \\
\text { time }(\%)\end{array}$ \\
\hline$M_{T D}$ corrections & 953 & 17.6 \\
\hline range focus & 34 & 0.6 \\
\hline generating $M_{D D}$ & 51 & 0.9 \\
\hline generating isolines & 4390 & 80.9 \\
\hline
\end{tabular}

a: performed with Intel ${ }^{\circledR}$ Core $^{\mathrm{TM}} \mathrm{i} 5-3330$ CPU @

$3.00 \mathrm{GHz} \times 4$ and 7.7 Gio Memory

elevation shift seems to have no influence (the relative error of the estimation does not exceed $8.7 \%$ ). For all yield values, the relative error is higher (12.9\% at 07-30-2019). At these dates, grapes did not reach their final volume and the mass of grapes might be overestimated. The reason is that between $0^{\circ}$ and $10^{\circ}$ are located horizontal metallic wires and irrigation hoses that may add clutter in the $H H$ configuration polarization. Therefore it is preferable to illuminate the beamscanned scene with an elevation angle higher than $10^{\circ}$. However, performing a beamscanning with the higher maximal elevation angle $\theta_{\max }$ generates segmented radar echoes at a larger range $R$. According to Fig 15a, these segmented radar echoes have a small impact on the yield estimation, as most of these echoes originate from the clutter (Class 0 ).

\section{F. Possible Reasons for Explaining the Overestimation of the Yield at the Date 09-23-2019}

Several reasons may explain the overestimation observed at the date 09-23-2019:

- In 2019, the radar was mounted on a platform which was $10 \mathrm{~cm}$ lower than the height used in 2020 . Then the beamscanned scene may include horizontal irrigation hoses generating more clutter in $\mathrm{HH}$ polarization configuration;

- Aliasing may occur on the beat frequency spectra delivered by the radar due to, e.g., the undesirable detection of obstacles or vine rows by the side lobe of the radar $R x$-antennas;

- The signal-to-noise ratio of the radar used in 2019 was found to be lower that one used in 2020 .

To confirm or refute these hypotheses, more investigations will be made in future works based on, e.g., the tuning the number of time samples $N_{S}$ or the modification of the radar height $h_{0}$.

\section{CONCLUSION}

Based on a novel statistical estimators, we have demonstrated in this paper that accurate estimation $(<10 \%)$ of the vineyard yield can be obtained before the harvest from using millimeter-wave radars mounted on a rover that moves along the furrows between vine rows. The estimation has been obtained for various grape varieties and meteorological conditions. As no particular precautions have been taken to the control the displacement of the rover (such as, its speed or lateral movement) or to minimize the vibrations, roll or pitch, these results are very encouraging and pave the way of the systematic estimation of the yield before the harvest in viticulture. The proposed technique may be applied to other type of fruits in orchards.

\section{ACKNOWLEDGMENT}

The Authors wish to thank E.Serrano, C.Gaviglio and the staff of IFV Sud-Ouest (Brames-Aigues, France) for their expertise and the availibility of the vineyard, as well as colleagues of MINC team (LAAS-CNRS, Toulouse, France) and Ovalie Innovation (Auch, France) for helping us to manually harvest and weighing the vine grapes.

\section{REFERENCES}

[1] J. V. Stafford, "Spatially Variable Field Operations," Computers and Electronics in Agriculture, vol. 14, no. 2, pp. 99-100, 1996.

[2] R. van Zuydam, Centimeter-Precision Guidance of Agricultural Implements in the Open Field by Means of Real Time Kinematic DGPS. John Wiley and Sons, Ltd, 1999, pp. 1023-1034.

[3] J. E. Sawyer, "Concepts of variable rate technology with considerations for fertilizer application," Journal of Production Agriculture, vol. 7, no. 2, pp. 195-201, 1994.

[4] R. Bramley and R. Hamilton, "Understanding variability in winegrape production systems," Australian Journal of Grape and Wine Research, vol. 10, no. 1, pp. 32-45, 2004.

[5] M. Bourgeon, C. Gée, S. Debuisson, S. Villette, G. Jones, and J. N. Paoli, "On-the-go multispectral imaging system to characterize the development of vineyard foliage with quantitative and qualitative vegetation indices ," Precision Agriculture, vol. 18, p. 293-308, 2017.

[6] L. Serrano, C. González-Flor, and G. Gorchs, "Assessing vineyard water status using the reflectance based Water Index," Agriculture, Ecosystems and Environment, vol. 139, no. 4, pp. 490-499, 2010.

[7] J. Rodríguez-Pérez, R. Plant, J.-J. Lambert, and D. Smart, "Using apparent soil electrical conductivity (ECa) to characterize vineyard soils of high clay content," Precision Agriculture, vol. 12, p. 775-794, 2011

[8] L. Tuccio, D. Remorini, P. Pinelli, E. Fierini, P. Tonutti, G. Scalabrelli, and G. Agati, "Rapid and non-destructive method to assess in the vineyard grape berry anthocyanins under different seasonal and water conditions," Australian Journal of Grape and Wine Research, vol. 17, no. 2, pp. 181-189, 2011

[9] R. Chamelat, E. Rosso, A. Choksuriwong, C. Rosenberger, H. Laurent, and P. Bro, "Grape Detection By Image Processing," in IECON 2006 - 32nd Annual Conference on IEEE Industrial Electronics, 2006, pp. 3697-3702.

[10] S. Liu, X. Zeng, and M. Whitty, "3DBunch: A Novel iOS-Smartphone Application to Evaluate the Number of Grape Berries per Bunch Using Image Analysis Techniques," IEEE Access, vol. 8, pp. 114663-114 674, 2020.

[11] C. Hacking, N. Poona, N. Manzan, and C. Pobelte-Echeverria, "Investigating 2-D and 3-D Proximal Remote Sensing Techniques for Vineyard Yield Estimation," Sensors (Basel), vol. 19(17), pp. 114663-114674, 2019.

[12] D. Henry, H. Aubert, and T. Véronèse, "Proximal Radar Sensors for Precision Viticulture," IEEE Transactions on Geoscience and Remote Sensing, vol. 57, no. 7, pp. 4624-4635, 2019.

[13] K. W. Eccleston, I. G. Platt, A. Jafari, A. Werner, C. Bateman, I. M Woodhead, J. Fourie, J. W. H. Hsiao, and P. Carey, "Observations from Radar Scans of Grape Vines Conducted Over a Growing Season," in 2019 IEEE Conference on Antenna Measurements Applications (CAMA), 2019, pp. 1-4.

[14] T. Véronèse, H. Aubert, and D. Henry, "System and Method for Estimating the Yield of a Cultivated Plot," Patent 3289380 , 29-04-2016.

[15] D. Henry and H. Aubert, "Isolines in 3D Radar Images for Remote Sensing Applications," in 2019 16th European Radar Conference (EuRAD), 2019, pp. 69-72.

[16] D. Henry, T. Marchal, J. Philippe, P. Pons, and H. Aubert, "Classification of radar echoes for identification and remote reading of chipless millimeter-wave sensors," IEEE Transactions on Microwave Theory and Techniques, vol. 69, no. 1, pp. 926-937, 2021.

[17] "Evalkits - Silicon Radar Wiki," https://siliconradar.com/wiki/Evalkits, accessed: 2021-02-04. 
[18] J. A. Richards, Remote Sensing with Imaging Radar. Springer-Verlag Berlin Heidelberg, 2009.

[19] J. Canny, "A Computational Approach to Edge Detection," IEEE Transactions on Pattern Analysis and Machine Intelligence, vol. PAMI-8, no. 6, pp. 679-698, 1986.

[20] "scipy.ndimage.zoom - SciPy v.1.6.2 Reference Guide," https:// docs.scipy.org/doc/scipy/reference/generated/scipy.ndimage.zoom.html, accessed: 2021-04-11.

[21] W. E. Lorensen and H. E. Cline, "Marching cubes: A high resolution 3d surface construction algorithm," SIGGRAPH Comput. Graph., vol. 21, no. 4, p. 163-169, Aug. 1987. [Online]. Available: https://doi.org/10.1145/37402.37422

[22] F. Pedregosa, G. Varoquaux, A. Gramfort, V. Michel, B. Thirion, O. Grisel, M. Blondel, P. Prettenhofer, R. Weiss, V. Dubourg, J. Vanderplas, A. Passos, D. Cournapeau, M. Brucher, M. Perrot, and E. Duchesnay, "Scikit-learn: Machine learning in Python," Journal of Machine Learning Research, vol. 12, pp. 2825-2830, 2011.

[23] D. L. Wilson, "Asymptotic properties of nearest neighbor rules using edited data," IEEE Transactions on Systems, Man, and Cybernetics, vol. SMC-2, no. 3, pp. 408-421, 1972.

[24] "scipy.optimize.curvefit - SciPy v.1.6.3 Reference Guide," https://docs. scipy.org/doc/scipy/reference/generated/scipy.optimize.curve_fit.html, accessed: 2021-04-29.

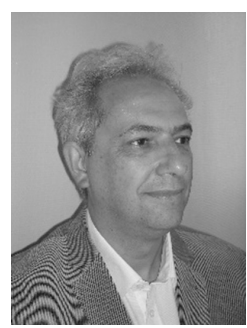

Hervé Aubert Hervé Aubert was born in Toulouse, France, in July 1966 . He received the Eng. Dipl. in July 1989 and the Ph.D. degree (with high-honors) in January 1993, both in Electrical Engineering and both from the National Polytechnic Institute (INPT), Toulouse, France. From April 1997 to March 1998 he was a Visiting Associate Professor at the School of Engineering and Applied Science, University of Pennsylvania, Philadelphia, USA. Since February 2001 Hervé Aubert is Professor at the National Polytechnic Institute. He has joined the Laboratory for the Analysis and Architecture of Systems (LAAS), National Centre for Scientific Research (CNRS), France, in February 2006. H. Aubert has performed research works on integral-equation and variational methods applied to electromagnetic wave propagation and scattering. Currently his research activities involve the electromagnetic modelling of complex (multi-scale) structures, and the wireless electromagnetic sensors. He has authored or co-authored one book (in French, 2003), 2 book chapters [Fractals: Theory and Applications in Engineering (Springer, 1999) and New Trends and Concepts in Microwave Theory and Techniques (Research Signpost, 2003)], 96 papers in refereed journals, 210 communications in international symposium proceedings, and 34 invited communications in international conferences, workshops and convened sessions. He holds 9 international patents. H. Aubert serves as a Subject Editor in-Chief (since 2020) and Subject Editor (since 2016) of Electronics Letters, after serving as an Associate Editor for this Journal from 2015 to 2016. He is a member of the editorial board of Sensors (since 2021), International Journal of Antennas and Propagation (since 2014), and he was a member of the editorial board for International Journal of Microwave Science and Techniques from 2010 to 2017. H. Aubert received the European Microwave Association Award in Recognition of Distinguished Service as General Chairman of the European Microwave Week 2015, the Best Reviewer Award of Information \& Communications Technology (ICT) Express in 2019, and the Certificate from IEEE Antennas and Propagation Society in Recognition and Appreciation for Exceptional Performance from May 1, 2019 to April 30, 2020 as a Reviewer of the IEEE Transactions on Antennas and Propagation.

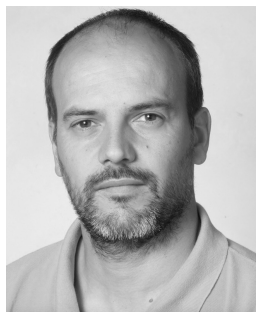

Patrice Galaup Patrice Galaup is graduated in agronomy from VetAgro Sup, Clermont-Ferrand, France. P.Galaup is project manager at Ovalie Innovation, Auch, France. His work focuses on the development of innovative agronomic solutions in agriculture and viticulture. Ovalie Innovation is a subsidiary company of 2 agricultural cooperative groups Maisadour and Vivadour, France. Ovalie Innovation objectives are to bring new productions and develop new business for cooperatives and farmers and also, thanks to collaborative R\&D projects, to implement new technologies for agricultural applications.

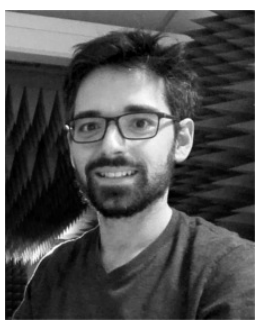

Dominique Henry Dominique Henry received the M.S. degree in electronical engineering and the $\mathrm{Ph} . \mathrm{D}$. degree from the Institut National Polytechnique de Toulouse, Toulouse, France, in 2012 and 2018, respectively. From 2013 to 2014, he was a Research Engineer with LAAS-CNRS, Toulouse. In 2014, he served in collaboration with LAAS-CNRS and Ovalie Innovation, Auch, France. His research interests include the use of microwave radars for agricultural applications, remote sensing of passive sensors, radar interrogation techniques, and development of smart antennas in constraint environments and microwave imaging. He works now with LAAS-CNRS as a post-doctoral researcher.

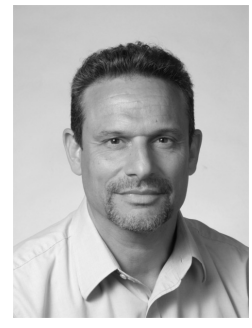

Thierry Véronèse Thierry Véronèse was born in Grenoble, France, in 1968. He received the Eng. Dipl. and Ph.D. degrees in industrial biotechnologies and food biochemistry from the National Institute of Applied Sciences of Toulouse, Toulouse, France, in 1995 and 1999, respectively. Since 2012, he is the Scientific Manager of Ovalie-Innovation, Auch, France. 